\title{
Stock Market Dispersion, the Business Cycle and Expected Factor Returns
}

Timotheos Angelidis ${ }^{\mathrm{a},},{ }^{,}$, Athanasios Sakkas ${ }^{\mathrm{b}}$ and Nikolaos Tessaromatis ${ }^{\mathrm{c}}$

a, ${ }^{*}$ Department of Economics, University of Peloponnese, Greece.

b Department of Accounting and Finance, Athens University of Economics and Business, Greece.

${ }^{c}$ EDHEC Business School and EDHEC Risk Institute, France.

Forthcoming in the Journal of Banking and Finance

\begin{abstract}
We provide evidence using data from the G7 countries suggesting that return dispersion may serve as an economic state variable in that it reliably predicts time-variation in economic activity, market returns, the value and momentum premia and market volatility. A relatively high return dispersion predicts a deterioration in business conditions, a higher value premium, a smaller momentum premium and lower market returns. Dispersion based market and factor timing strategies outperform out-of-sample buy and hold strategies. The evidence are robust to alternative specifications of return dispersion and are not driven by US data. Return dispersion conveys incremental information relative to idiosyncratic risk.
\end{abstract}

Keywords: Stock Market Return Dispersion, Business Cycle, Market and Factor Returns. JEL Classification: G12, G14.

"Corresponding author. Tel.: +30 2710 230128; fax: +30 2710230139.

E-mail addresses: tangel@uop.gr (T. Angelidis), asakkas@aueb.gr (A. Sakkas), nikolaos.tessaromatis@edhec.edu (N. Tessaromatis) 


\section{Introduction}

Stock market return dispersion (RD) - defined as the cross sectional standard deviation of returns from either individual stocks or from disaggregate stock portfolios provides a timely, easy to calculate at any time frequency, model free measure of volatility. It measures the extent to which stocks move together or are diverging and has been used by both finance academics and practitioners to measure trends in aggregate idiosyncratic volatility, ${ }^{1}$ investors' herding behavior, ${ }^{2}$ micro-economic uncertainty, ${ }^{3}$ trends in global stock market correlations, ${ }^{4}$ as an indicator of potential alpha and a proxy for active risk, ${ }^{5}$ and as a leading countercyclical state variable. ${ }^{6}$ We provide comprehensive evidence across seven major equity markets suggesting that RD has significant predictive power for the business cycle, stock returns, the value and momentum premia, and market volatility.

\footnotetext{
${ }^{1}$ Garcia, Mantilla-Garcia and Martellini (2013).

${ }^{2}$ Christie and Huang (1995) use cross sectional volatility to capture herd behavior in stock markets.

${ }^{3}$ Bloom (2009) and Bloom, Floetotto, Jaimovich, Saporta-Eksten and Terry (2012).

${ }^{4}$ Solnik and Roulet (2000) make the case for the use of RD as an instantaneous measure of correlation that provides a dynamic estimate of the trends in correlation using only cross-sectional data.

${ }^{5}$ Silva, Sapra and Thorley (2001) find that the dispersion of mutual fund returns can be explained by RD. Connor and $\mathrm{Li}$ (2009) show that RD can explain part of hedge fund returns not explained by the standard Fung and Hsieh (2004) hedge fund risk factors. From a practical perspective, Russell Investments and Parametric Portfolio Associates publish since 2010 (http://www.parametricportfolio.com/crossvol) a set of indexes to track cross sectional volatility covering each of the major regions, investment styles and economic sectors.

${ }^{6}$ Gomes, Kogan and Zhang (2003) present a theoretical link between RD, the economy, future market returns and volatility. Empirical evidence on the predictive ability of RD for US stock returns are provided by Garcia, Garcia-Mantilla and Martellini (2013) and Maio (2014) and for the value and momentum premia by Stivers and Sun $(2010,2013)$.
} 
$\mathrm{RD}$ is an instantaneous measure of aggregate volatility calculated from returns without the need for specifying a particular factor model that drives stock returns. Cross sectional measures of volatility are closely related with time series based measures of volatility (see among others Goyal and Santa-Clara, 2003 and Garcia, Mantilla-Garcia and Martellini, 2013).

Our study focuses on RD formed from monthly individual stock returns or from disaggregate stock portfolios, both value-weighted and equal-weighted. The first contribution is to study in depth the properties of RD across the G7 countries adding to the evidence from the US market. ${ }^{7}$ In particular we are interested in the commonality of its behavior across countries. Our evidence suggests that country RD is strongly positively correlated across markets with a common factor driving return dispersion across the G7 countries. The significance of the common factor has increased during the last decades.

Interest in $\mathrm{RD}$ among academics and practitioners has further increased since it was realized that it could be a proxy of future economic conditions and a predictor of the business cycle. Figure 1 depicts the time-series history of country RDs against recession dates for the period 1980-2012 for the G7 countries. Figure 1 shows evidence that RD follows a business-cycle pattern being low during expansions and high during recessions.

Stock market dispersion as a measure of the intensity of structural shocks to the economy was first used by Loungani, Rush and Tave (1990) following a conjecture by Black (1987, 1995). More recently Bloom (2009) and Bloom, Floetotto, Jaimovich,

\footnotetext{
${ }^{7}$ Using data from major markets outside the US minimizes the biases that arise due to data snooping (Lo and MacKinley, 1990) and offers an independent assessment of the empirical findings.
} 
Saporta-Eksten and Terry (2012) argue that uncertainty shocks are an important driver of business cycles. Chen, Kannan, Loungani and Trehan (2011) find that return dispersion has a strong effect on long duration unemployment. Garcia, Mantilla-Garcia and Martellini (2013) argue that return dispersion is related to consumption volatility, a measure of economic uncertainty in the inter-temporal asset pricing model of Bansal and Yaron (2004). The second contribution of our paper is a study of the relation between RD and future economic conditions. Our evidence suggests that, after controlling for financial and economic variables known to predict the economy, RD is a strong predictor of the business cycle and economic growth. A higher return dispersion over the last three months indicates a higher probability that the economy will be in a recession in the current month. Higher RD is associated with an increase in unemployment and a fall in future economic activity.

There is now a rich empirical literature on the predictive ability of non-market measures of volatility like idiosyncratic or average volatility or RD for future stock market returns. Goyal and Santa-Clara (2003) present evidence suggesting that there is a positive relation between average variance and future stock returns. Subsequently published papers by Bali, Cakici and Levy (2008) and Wei and Zhang (2005) argue that the Goyal and Santa-Clara (2003) findings are sample specific and not robust to the definitions of average variance. Pollet and Wilson (2010) and Chen and Petkova (2012) find a negative relation between stock returns and past average volatility.

Evidence on the relation between RD and multiple horizon returns are provided in Maio (2014). Using monthly portfolio returns to measure RD, Maio (2014) finds a negative and statistically significant relation for the US market. The negative relation 
between RD and future returns is consistent with the evidence in Guo and Savickas (2008) for the G7 countries using idiosyncratic volatility instead of RD. Garcia, MantillaGarcia and Martellini (2013) using a measure of RD based on the average of daily RDs find a positive relation between RD and subsequent monthly and daily US market returns. The evidence on the predictive ability of RD, mainly from the US market, remains controversial and calls for further study across different markets.

Stivers and Sun (2010) provide a direct test of the ability of RD to predict value and momentum premia. Using US stock market data for the period 1965-2005 they find that $\mathrm{RD}$ is positively related with the value premium and negatively related with the momentum premium. They conjecture that $\mathrm{RD}$ is "a leading countercyclical variable" which varies with the state of the economy, evidence consistent with the hypothesis that RD might be informative about changes in the investment opportunity set. We test whether $\mathrm{RD}$ can predict market returns and the value, size and momentum premia at twelve month horizon. Our evidence suggests that return dispersion observed at time $t$ predicts future twelve month market returns and the value and momentum premia. The predictive ability of RD remains intact when we control for other variables that predict stock returns and factor premia. Dispersion is a statistically and economically significant predictor of future market and factor returns.

The evidence on the ability of RD to predict future stock returns and factor premia is consistent with the view that return dispersion is a state variable in the spirit of Merton's (1973) intertemporal CAPM. Chen (2003) extends Campbell's (1996) version of the ICAPM to include in addition to time-varying returns, time-varying volatility as descriptors of the investment opportunity set. If $\mathrm{RD}$ is a state variable it should forecast 
returns or volatility. We test this conjecture and find that RD is an important predictor of future market volatility.

We implement several robustness tests to examine the sensitivity of our results to (i) different sample periods (ii) alternative RD construction methodologies and (iii) the exclusion of the US from our database. We provide evidence suggesting that our results are not sample specific, are robust to different measures of RD and remain intact when the US is excluded from the data.

In the last part of the paper we examine the differences between RD and aggregate idiosyncratic risk in light of Garcia, Mantilla-Garcia, and Martellini's (2013) finding that idiosyncratic volatility and RD are highly correlated. We find that both measures are related to subsequent economic conditions and future market returns and factor premia. When we include both in the predictive regressions of factor and market returns we find that $\mathrm{RD}$ drives out the predictive power of idiosyncratic volatility. Value and momentum time strategies based on return dispersion driven forecasts provide small but economically significant improvement compared to timing strategies based on idiosyncratic volatility.

The rest of this paper is organized as follows. Section 2 presents the data and summary statistics and examines if there is a common factor that affects return dispersion in G7 markets. Section 3 provides evidence on the predictive ability of RD for future economic activity and the business cycle, market and factor returns and market volatility. In Section 4 we assess the robustness of our findings over different samples, different RD measures and the exclusion of US data. Section 5 explores the information content of RD and idiosyncratic risk. Section 6 concludes the paper. 


\section{Data and Dispersion Measures}

The data set is obtained from Thomson DataStream and covers all stocks (dead or alive) from July 30, 1980 to December 31, 2012 (390 monthly observations) in the G7 markets: Canada, France, Germany, Italy, Japan, UK, and US. Returns are calculated in US dollars. Following Ince and Porter (2006), Hou, Karolyi and Kho (2011), Guo and Savickas (2008), and Busse, Goyal and Wahal (2013) we impose various filters to minimize the risk of data errors and to account for potential peculiarities of the dataset (see Appendix B for details).

We calculate for each market the monthly cross sectional variance at time $t\left(C S V_{t}\right)$ using the following equation:

$$
C S V_{\mathrm{t}}=\sum_{\mathrm{i}=1}^{\mathrm{N}} \mathrm{w}_{\mathrm{it}}\left(\mathrm{r}_{\mathrm{it}}-\mathrm{r}_{\mathrm{mt}}\right)^{2}
$$

where $r_{i t}$ is the return of stock i in month $t, r_{m t}$ is the return of the value weighted market portfolio in month $\mathrm{t}, \mathrm{N}$ is the number of stocks and $\mathrm{w}_{\mathrm{it}}$ is defined as $w_{i, t}=\frac{1}{N}$ for the equally weighted cross sectional variance $\left(\operatorname{CSV}_{e w, t}\right)$ and as $w_{i, t}=$ $\frac{\text { Market cap of stock i in month } t-1}{\text { Total market cap }}$, for the market capitalization weighted cross sectional variance $\left(C S V_{c w, t}\right)$. Return dispersion equals $\sqrt{C S V_{\mathrm{t}}}$. We construct country and world based dispersion measures by using stock returns from the country and world universes, respectively. 
Following Stivers and Sun (2010) and Maio (2014) we create an equally weighted measure of dispersion based on 100 portfolios formed using all stocks from the G7 stock markets. We also calculate a capitalization weighted measure of portfolio based RD. In particular at the end of each June, we sort all stocks in 100 portfolios based on market capitalization and on the ratio of book equity to market equity. The portfolios are the intersections of 10 portfolios formed on market capitalization and 10 portfolios formed on the ratio of book equity to market equity. We calculate the value weighted monthly portfolio returns and then calculate equally and capitalization weighted dispersion. Using portfolios instead of stocks to measure dispersion avoids the influence of extreme individual stock returns and therefore provides a less noisy measure of return dispersion than measures based on individual stock returns. Stivers and Sun (2010) argue that portfolio based measures of dispersion perform similarly but generally better than firm level dispersion measures.

We follow closely the methodology used by Fama and French (1992) to construct the style portfolios. At the end of June we sort all stocks in a country based on their market capitalization and their book value per share to form the SMB and HML portfolios. We set as missing negatives or zero values of book value per share. The fiscal year ending in year $t-1$ is matched with the returns and the market capitalization of year $t$ and hence there is no looking ahead bias in our dataset. At the end of June of each year, we form the six portfolios of Fama and French (1993) and calculate the value weighted monthly returns over the next 12 months. To create the SMB factor we use the median of the market value, while for the book to market factor (HML) we set the breakpoints of the $\mathrm{BM}$ ratio at the $30^{\text {th }}$ and $70^{\text {th }}$ percentiles. Finally, we calculate the momentum factor 
(MOM) for month $\mathrm{t}$ as the cumulative monthly returns for $\mathrm{t}-1$ to $\mathrm{t}-12$. Combined with the market capitalization we construct every month six value weighted portfolios to form the momentum factor by using the median of the market value and the $30^{\text {th }}$ and $70^{\text {th }}$ percentiles of the momentum.

\subsection{Descriptive statistics}

Panels $\mathrm{A}$ and $\mathrm{B}$ of table 1 present descriptive statistics for equally weighted country $\left(R D_{\text {country }}^{e w}\right)$, world $\left(R D_{\text {world }}^{e w}\right)$ and portfolio $\left(R D_{\text {portfolio }}^{e w}\right)$ based measures of dispersion. It also shows statistics for capitalization weighted country ( $\left.R D_{\text {country }}^{c w}\right)$, world $\left(R D_{\text {world }}^{c w}\right)$ and portfolio $\left(R D_{\text {portfolio }}^{c w}\right)$ measures of dispersion. All measures are calculated as a 3-month average of monthly cross sectional return dispersion to mitigate the possible effect of large outliers as in Stivers and Sun (2010) and Maio (2014).

The average equally weighted country-based monthly return dispersion equals $8.50 \%$ and ranges from $6.98 \%$ (Italy) to $11.19 \%$ (Canada). The average world equally weighted dispersion at $9.64 \%$ is generally higher but less volatile than country dispersion measures. Capitalization weighted country dispersion measures are generally lower than equally weighted dispersion measures (averaging 6.66\% across countries) reflecting the larger weighting of the less volatile large cap stocks. Average capitalization weighted world dispersion has a smaller mean (7.64\%) and lower volatility (1.84\%) than the respective equally weighted dispersion. Portfolio based measures of dispersion are much lower than stock based measures reflecting the lower volatility of portfolios due to diversification of idiosyncratic risk. All RD measures are non-normally distributed exhibiting positive skewness and excess kurtosis. 


\subsection{Correlation structure of return dispersion measures.}

Panel A of table 2 presents the correlations of return dispersion across the G7 countries, the world and portfolio based measures of RD. The average correlation of $R D_{\text {country }}^{\text {ew }}$ measures across the $\mathrm{G} 7$ countries is 0.59 , the highest correlation is between France and Germany (0.82) and the lowest between Italy and Japan (0.28). Capitalization based country RD measures are more correlated than equally weighted measures with the average correlation across countries equal to 0.69 . The highest correlation pair is US and Canada (0.89) and the lowest correlation pair is Japan and Italy (0.43). The high correlation between country RD measures suggests that periods of high correlation in one market are associated with high risk in other markets. The high correlations also suggest that country RD measures share one or more common factors, an issue that is further investigated in section 2.3.

The average correlation between country based RD measures and world dispersion is $0.76 . R D_{\text {world }}^{\text {ew }}$ has the highest correlation with the US (0.93) and the lowest with Italy (0.50). Excluding US stocks from the calculation of $R D_{\text {world }}^{\text {ew }}$ leaves the average correlation between the world and country RDs unchanged. Capitalization weighted measures of $\mathrm{RD}$ produce slightly higher correlations between world and country based measures ( 0.78 when US stocks are included and 0.75 when US stocks are excluded). The strong correlations between country and world RD is consistent with the presence of a world factor in country dispersions. 
Return dispersion measures based on world portfolios have lower correlation with country based measures. For the equally (capitalization) weighted measures the average correlation is equal to $0.52(0.40)$. Correlations are higher with world RD measures $(0.73$ for the equally weighted and 0.68 with the capitalization weighted), a finding suggesting the presence of common factors across all measures of RD.

\subsection{Commonality in return dispersion measures}

To investigate further the commonality in $\mathrm{RD}$ measures, we perform principal component analysis of country RD. We find that the first principal component explains, for the equally (capitalization) weighted measures, approximately $66.07 \%(73.88 \%)$ of the variation of the cross sectional return variance. The first principal component has significant loadings to country RD measures, suggesting that perhaps the world RD might be a good proxy for it. Indeed the correlation between the first principal component and world RD is 0.95 (0.92). The second principal component explains $11.09 \%(8.56 \%)$ of the RD variability. We also perform a subsample analysis to examine the per period importance of the first component. We split the sample in two periods: 1980-1996, and 1997-2012. For the first and the second period the explanatory power of the first component equals $32.89 \%(40.80 \%)$, and $74.52 \%$ (84.59\%), respectively suggesting that the importance of the common global factor has increased over time. ${ }^{8}$

\footnotetext{
${ }^{8}$ To examine further the impact of the global return dispersion factor on individual country cross sectional return variation, we modify the methodology used by Brockman, Chung, and Perignon (2009) in their study of a common global liquidity factor in exchange-level liquidity. Specifically, we estimate the equation: $R D_{C, t}=\alpha+\beta_{0} R D_{G, t+1}+\beta_{1} R D_{G, t}+\beta_{2} R D_{G, t-1}+\gamma_{0} A C_{C, t}+\varepsilon_{C, t}$, where $R D_{C, t}$ and $A C_{C, t}$ are the return dispersion and average stock correlation of country $C, R D_{G, t}$ is the world return dispersion (equally or capitalization weighted) excluding country $C$. We calculate the average correlation using all stocks in a market at time $\mathrm{t}$ defined as $A C_{t}=\sum_{i=1}^{N} \sum_{j=1}^{N} w_{i t} w_{j t} \operatorname{corr}\left(r_{i t}, r_{j t}\right)$. We find that $\beta_{1}$ equals 0.468 (t-statistic of 6.33) and hence an increase of the global factor affects positively country RD. The explanatory power of the model increased over time (from $23.58 \%$ to $68.84 \%$ ). Bekaert, Hodrick, and Zhang (2012) find a
} 


\section{The Forecasting Ability of Return Dispersion}

In this section we investigate the forecasting power of return dispersion for business conditions and the market, size, value and momentum premia and market volatility. The forecasting regression is: $Y_{t}=\alpha+\beta X_{t-1}+\varepsilon_{t}$, where $Y_{t}$ is for the state of the economy the business cycle dummy, unemployment or the ADS business conditions index. ${ }^{9}$ For the return and premia forecasting equation $Y_{t}$ is the 12-month market return or the size, value or momentum premia. ${ }^{10} X_{t-1}$ includes RD, and a set of control variables found in past research to forecast the future state of the economy, market volatility, market return and factor premia. We use world equally and capitalization weighted RD as the main measures of dispersion and examine in section 4 the robustness of the results to alternative measures.

\section{1. $R D$ as a predictor of the state of the economy}

Existing literature on the relation between stock market volatility and future macroeconomic developments has focused on the question of what macro variables predict future volatility. ${ }^{11}$ The ability of volatility, market or idiosyncratic, to predict future economic conditions has received less attention. Lilien (1982) provides a

similar increase in the correlation of asset specific risk of G7 countries with the US. The evidence suggests that global return dispersion drives country cross-sectional variation. The increased importance of global $\mathrm{RD}$ over the last three decades is consistent with greater economic and financial integration. The detailed results are available upon request from the authors.

${ }^{9}$ For more information on the ADS business index, the reader is referred to the work of Aruoba, Diebold and Scotti (2009). The sample period for the ADS equation ends on December 2009 because the data for the G7 countries are not available after 2009.

${ }^{10} \mathrm{We}$ focus on a yearly forecasting horizon following the evidence in Maio (2014) showing that the predicting ability of RD is stronger for holding periods greater than one or six months. Using monthly data we also find consistent but generally weaker results compared to annual returns.

${ }^{11}$ Schwert (1989), Hamilton and Lin (1996), Engle and Rangel (2008) and Adrian and Rosenberg (2008) among others. 
theoretical link between RD and unemployment. According to Lilien (1982) cyclical variations in unemployment is the result of shocks to individual sectors that in turn cause reallocation of labor across sectors. Since job search is time consuming, sectoral shifts due to an adverse shock tend to be accompanied by a rise in unemployment. Bloom (2009) and Bloom, Floetotto, Jaimovich, Saporta-Eksten and Terry (2012) argue that uncertainty shocks lead the business cycle as they cause a reduction in the reallocation of labor and capital, lower productivity and a significant fall in economic activity. They use dispersion and market volatility to measure time varying micro and macro uncertainty, respectively. Chen, Kannan, Loungani and Trehan (2011) find that an increase in market volatility is associated with an increase in short duration unemployment. Dispersion on the other hand, has a strong effect on long duration unemployment. Garcia, MantillaGarcia and Martellini (2013) show that return dispersion is countercyclical (low economic growth coincides with high cross-sectional volatility) and is linked with variables that are known to predict future stock returns. They find a positive relation between dispersion and consumption volatility and a negative relation with inflation volatility.

In this section we provide evidence on whether RD provides incremental information about future economic activity for the economies of the G7 countries. We measure the state of the economy using three variables: a business cycle dummy ( $1=$ recession, $0=$ expansion) for each of the $\mathrm{G} 7$ countries provided by the Economic Cycle Research Institute, ${ }^{12}$ the monthly ADS business conditions index which is designed to

\footnotetext{
${ }^{12}$ The business cycle dates are obtained from the Economic Cycle Research Institute (http://www.businesscycle.com/home) that publishes Business Cycle Peak and Trough Dates, for 22
} 
track real business conditions and the unemployment rate (UE). To ensure that RD conveys additional information we control for the information content of other economic variables found in the literature to predict economic activity. The set of control variables includes: $^{13}$ short-term nominal interest rate (INT); market return $(M k t)$; average correlation $(A C)$; the term spread (TS) defined as the difference between the ten-year treasury constant maturity rate and the three-month T-Bill rate; the dividend yield $(D Y)$ on the value weighted stock index and the unemployment rate $(U E)$. The data are taken from DataStream. Italy and France are not included in the estimation due to the unavailability of the monthly unemployment rate for the whole period.

We investigate the forecasting ability of RD by estimating the following panel regressions:

$$
\begin{aligned}
\operatorname{Probit}\left(D_{t}\right)= & \gamma_{0}+\gamma_{1} R D_{t-1}+\gamma_{2} A C_{t-1}+\gamma_{3} M k t_{t-1}+\gamma_{4} T S_{t-1}+\gamma_{5} d U E_{t-1} \\
& +\gamma_{6} I N T_{t-1}+\gamma_{7} D Y_{t-1}+\epsilon_{t}
\end{aligned}
$$

countries, for the period 1948-2012 applying the same methodology used to determine the official US business cycle dates.

${ }^{13}$ Studies using financial and economic variables to predict future economic activity include Chen (1991), Estrella and Hardouvelis (1991), Harvey (1991), Stock and Watson (2003), Ang, Piazzesi and Wei (2006) and Fornari and Mele (2009). We include average correlation as a predictor variable instead of market volatility following Pollet and Wilson's (2010) argument that average correlation is a better proxy for aggregate risk. Another advantage of using average correlation as a proxy for aggregate risk in the predictive regression is that it avoids possible multicollinearity issues arising from the high correlation between RD and market volatility. We calculate $\mathrm{AC}$ as a 3-month average of monthly average correlation. $d U E_{t}$ is the growth in unemployment rate and is calculated as $d U E_{t}=\ln \left(\frac{U E_{t}}{U E_{t-1}}\right)$. 


$$
\begin{gathered}
A D S_{t}=\gamma_{0}+\gamma_{1} R D_{t-1}+\gamma_{2} A C_{t-1}+\gamma_{3} M k t_{t-1}+\gamma_{4} T S_{t-1}+\gamma_{5} d U E_{t-1} \\
+\gamma_{6} I N T_{t-1}+\gamma_{7} D Y_{t-1}+\gamma_{8} A D S_{t-1}+\epsilon_{t} \\
d U E_{t}=\gamma_{0}+\gamma_{1} R D_{t-1}+\gamma_{2} A C_{t-1}+\gamma_{3} M k t_{t-1}+\gamma_{4} T S_{t-1}+\gamma_{5} d U E_{t-1} \\
+\gamma_{6} I N T_{t-1}+\gamma_{7} D Y_{t-1}+\epsilon_{t}
\end{gathered}
$$

The panel model for equations 2, 3 and 4 uses country dummies and clusters the standard errors by country, allowing for observations from the same country in different years to be correlated. ${ }^{14}$ For equations 3 and 4 we also adjust the standard errors by using the Newey-West procedure (Newey and West, 1987) modified for use in a panel data set.

Table 3 presents the estimation results of equations 2-4 for the business cycle, ADS business conditions index and the unemployment rate. Control variables are included in all regressions but for brevity we do not show coefficient estimates in table 3. Using all countries in a pooled regression we find a positive and statistically significant relation between the business cycle dummy and equally weighted world dispersion. A higher world dispersion over the last three months indicates a higher probability that the economy will be in a recession for the current month. Using the ADS business condition as a proxy for economic activity we also get a strong and statistically significant relation with return dispersion (see coefficient estimates in column 4 of table 3). A higher return dispersion is followed by worsening business conditions. The unemployment rate is negatively related with the state of the economy. If return dispersion is a countercyclical variable it should be positively associated with the unemployment rate. The coefficient of

\footnotetext{
${ }^{14}$ For more information on the methodology, refer to the work of Petersen (2009).
} 
the world return dispersion measure is 0.200 and statistically significantly different from zero (t-statistic 5.319). Capitalization weighted world return dispersion produces very similar coefficients estimates and t-statistics for the all proxies of economic activity and the business cycle.

The evidence on the predictive ability of return dispersion are consistent with previous evidence from the US market. It is possible that the observed relationship found when pooling information across countries is driven by US data. To assess the sensitivity of the estimation results to the inclusion of the US data we re-estimate equations 2-4 excluding the US from the full panel of countries ${ }^{15}$ and show the results in rows 4-6 of table 3. Excluding the US could be regarded as an out-of-sample test of the empirical evidence reported for the US market. Excluding the US produces coefficient estimates for world return dispersion that are very similar to estimates that include data from the US. With the exception of the ADS business conditions index, the t-statistics suggest similar significance levels. Use the capitalization weighted measure of world return dispersion produces similar results.

Table 3 also shows evidence on the pervasiveness of the ability of world return dispersion to predict the state of economy by looking at the country by country evidence. For the business cycle dummy the relation between the state of the economy and equally weighted world dispersion is positive and statistically different from zero for four of the five countries. For the capitalization weighted measure of world return dispersion the number of countries with statistically significant coefficients is three. The only exception

\footnotetext{
${ }^{15}$ In section 4 we examine in addition the effect of excluding US stocks from the calculation of the world $\mathrm{RD}$ measures.
} 
to the positive relation between dispersion and the business cycle dummy is the UK for which the estimated coefficient is negative.

For the ADS business condition index and for three of the five countries (the exceptions are Canada and Germany) the estimated coefficient is negative but statistically significant only for the US. The insignificance of dispersion in the panel that excludes the US suggests that for this variable the full panel results are driven primarily by US data.

World return dispersion (equally or capitalization weighted) is positive and statistically significantly related with unemployment rate for four of the five countries (the exception is Germany).

To summarize, table 3 provides strong evidence that world return dispersion helps forecast economic activity and the business cycle. The ability of RD to predict future economic developments remains intact when we control for the information content of other variables found in the literature to predict the business cycle. The relation between world return dispersion and the economy is pervasive across countries and remain significant when the US is excluded from the sample.

\subsection{Does return dispersion forecast market returns and factor payoffs?}

The evidence in the previous section suggests that $\mathrm{RD}$ is a pervasive financial variable and potentially a proxy for risk factors omitted from the single factor CAPM. A relative higher RD signals a deterioration of future economic activity and an increased probability that the economy enters a recession. It is also well accepted in the finance literature that market and factor premia are time-varying and dependent on the state of the 
economy.${ }^{16}$ The evidence from the cyclical nature of $\mathrm{RD}$ and the time-varying behavior of market and factor premia jointly suggest that RD might be a good predictor of future returns and factor premia.

Guo and Savickas (2008) and Maio (2014) find a negative and statistically significant relation between idiosyncratic volatility and RD and subsequent US market returns. In contrast, Garcia, Mantilla-Garcia and Martellini (2013) document a positive relation between RD and the US stock market. Stivers and Sun (2010) provide a direct test of the ability of RD to predict value and momentum premia. Using US stock market data for the period 1965-2005 they find that RD is positively related with the value premium and negatively related with the momentum premium. They conjecture that RD is "a leading countercyclical variable" which varies with the state of the economy.

In this section we extend the work of Stivers and Sun (2010), Garcia, MantillaGarcia and Martellini (2013) and Maio (2014) to provide new evidence for the predictive ability of RD for market returns and the size, value and momentum premia for the stock markets of the G7 countries. Pooling data from all countries produces more efficient coefficient estimates whilst the use of data from major markets outside the US minimizes the effects of data snooping and provides an independent assessment of the available empirical evidence.

More specifically, we estimate the following panel regressions at annual frequencies to investigate the predictive ability of RD:

\footnotetext{
${ }^{16}$ Stivers and Sun (2010) provide a review of the academic literature on the cyclical properties of the value and momentum premia.
} 


$$
\begin{aligned}
& M k t_{t+11}=\gamma_{0}+\gamma_{1} R D_{t-1}+\gamma_{2} A C_{t-1}+\gamma_{3} D Y_{t-1}+\gamma_{4} I N T_{t-1}+\epsilon_{t} \\
& H M L_{t+11}=\gamma_{0}+\gamma_{1} R D_{t-1}+\gamma_{2} A C_{t-1}+\gamma_{3} D Y_{t-1}+\gamma_{4} I N T_{t-1}+\epsilon_{t} \\
& S M B_{t+11}=\gamma_{0}+\gamma_{1} R D_{t-1}+\gamma_{2} A C_{t-1}+\gamma_{3} D Y_{t-1}+\gamma_{4} I N T_{t-1}+\epsilon_{t} \\
& M O M_{t+11}=\gamma_{0}+\gamma_{1} R D_{t-1}+\gamma_{2} A C_{t-1}+\gamma_{3} D Y_{t-1}+\gamma_{4} I N T_{t-1}+\epsilon_{t}
\end{aligned}
$$

where $M k t_{t+11}$ is the payoff of the market index over holding-period months $t$ to $t+11$ $H M L_{t+11}$ is the payoff of the HML factor over holding-period months $t$ to $t+11$, $S M B_{t+11}$ is the payoff of the SMB factor over holding-period months $t$ to $t+11$, $M O M_{t+11}$ is the payoff of the MOM factor over holding-period months $t$ to $t+11$,

We regress long-horizon returns on $\mathrm{RD}$ and other control variables observed monthly. Overlapping returns induces by construction a strong autocorrelation pattern to the dependent variable. Using standard inference techniques in regressions involving overlapping dependent variables leads to misleading estimates of the coefficient standard errors and statistical inference. Britten-Jones, Neuberger and Nolte (2011) propose a method to overcome this problem by transforming the variables onto non-overlapping series. They show that the coefficients of the two regressions (overlapping vs. nonoverlapping) are identical and through Monte Carlo analysis they demonstrate that their method produce more accurate standard errors than the conventional adjustments for regressions with overlapping observations (White, 1980, and Newey and West, 1987). Therefore, in order to estimate the long-horizon $(n=11)$ equations, we first transform the variables into their non-overlapping counterparts and then we estimate equations 5,6 , 7, and 8 as panel regressions using the methodology developed by Petersen (2009). 
Table 4 presents the panel regressions of twelve month market returns, value, size, and momentum on lagged return dispersion and control variables. The panel regression includes control variables whose coefficient estimates are not shown in the table for the sake of brevity.

By pooling data across countries we find a negative and statistically significant relation between equally weighted world dispersion and subsequent market returns. Excluding the US from the panel data does not affect the coefficient estimate and its statistical significance. The estimated coefficients of return dispersion are negative across all countries and statistically significant for Germany and Italy. The results are robust to the use of the capitalization weighted measure of world return dispersion (the estimated coefficients of RD are significant for France, Germany and Italy).

The negative relation between $\mathrm{RD}$ and subsequent market is robust to the investment horizon. When we use a monthly horizon to re-estimate equation 5 we find a strong negative relation between market returns and the equally (coefficient -0.146 , $t$ statistic -2.303) and capitalization (coefficient -0.167, t-statistic -2.544) weighted RD. The evidence are consistent with results of Guo and Savickas (2008) and Maio (2014) but contradicts the evidence presented in Garcia, Mantilla-Garcia and Martellini (2013) for the US market. Garcia, Mantilla-Garcia and Martellini (2013) use a monthly RD measure calculated as the monthly average of daily $\mathrm{RD}$, to predict monthly market returns and find a positive but insignificant relation with capitalization weighted market return. They find a significantly positive relation between daily market returns and RD. The contradictory results reported in Garcia, Mantilla-Garcia and Martellini (2013) compared to the evidence in this paper and Maio (2014) might reflect the use of daily 
rather than monthly return data used to calculate RD. The use of daily data to calculate RD could introduce a microstructure bias driven by the bid-ask spread. Han and Lesmond (2011) and Han, Hu and Lesmond (2014) show that due to the bid-ask bounce in daily returns, estimates of volatility based on daily data will be biased and could lead to misleading inferences.

A higher world dispersion is associated with better performance of value-versusgrowth strategy over the subsequent year. The coefficient of world dispersion is positive and statistically different from zero for panels including and excluding the US. The relation is consistently positive across all countries and dispersion measures. For both the equally and capitalization weighted measure of world dispersion the coefficients are statistically significant for four of the seven countries.

Using the full panel of countries we find a negative relation between world dispersion and the momentum premium. A higher world dispersion is associated with weaker performance for a momentum strategy over the subsequent year. Excluding the US from the panel makes little difference to the estimates. The relation is negative across countries and statistically significant (at the $10 \%$ level) for three of the seven countries (four out of seven when the capitalization weighted measure of dispersion is used). The evidence is consistent with the results reported in Stivers and Sun (2013) for the US market. They study the relation between lagged $\mathrm{RD}$ and relative strength market strategies and provide evidence in favor of the view that the relation is negative for both medium-run and long-run strategies.

Finally, we find no relation between the size premium and equally weighted world dispersion with panel data including and excluding the US. Looking at individual 
country results we find a negative but statistically insignificant relation for five countries, a positive relation for the UK and a positive and statistically significant coefficient for the US. Similar results are obtained with the capitalization weighted measure of return dispersion.

The relation between the world return dispersion and market returns and factor premia is economically significant. A one standard deviation increase of world return dispersion is associated with a $-3.73 \%(-1.741 \times 0.214)$ decrease in market returns, a $3.53 \%(1.650 \times 0.214)$ increase in the value premium and a $-3.85 \%(-1.800 \times 0.214)$ fall in the momentum premium.

The evidence on the relation between dispersion and market returns and the value premium are consistent with the evidence in Guo and Savickas (2008) who argue that idiosyncratic volatility, a volatility measure correlated with dispersion, is a proxy for changes in the investment opportunity set. For the G7 countries they find a negative relation between idiosyncratic volatility and market returns (statistically significant for two of the seven countries) and positively related to the value premium (statistically significant for four of the seven countries). ${ }^{17}$ We examine in section 5 whether dispersion is a better measure of the opportunity set than idiosyncratic volatility.

Guo and Savickas (2008) and Maio (2014) find that the information content in idiosyncratic volatility (Guo and Savickas) and RD (Maio) is more reliable when also controlling for the realized market volatility. To examine whether the relation between $\mathrm{RD}$ and subsequent market returns and premia strengthens when we use data from the G7

\footnotetext{
${ }^{17}$ Compared to the results in Guo and Savickas (2008), in this paper the capitalization weighted dispersion measure is important for three (four) of the seven countries for the market (value). In our research, in addition to country evidence, we also pool information across countries.
} 
countries, we replace average correlation (AC) with market volatility ${ }^{18}$ and re-estimate equations 5 to 8 . In the presence of market volatility the coefficient of equally weighted $\mathrm{RD}$ remains statistically significant and marginally stronger compared with RD coefficient estimated when market volatility is not included in the predictive regressions. In particular, the coefficient of RD when predicting market returns is reduced from 1.721 (t-statistic -3.056) when market volatility is not included in the regression, to 1.916 (t-statistic -3.167) when market volatility is one of the control variables. Similar to the evidence reported in Guo and Savickas (2008) we find that the coefficient of market volatility becomes positive from negative when we include both volatility variables in the regression. Controlling for market volatility strengthens the coefficient of RD for the value premium (from 1.712 to 1.779 ) but weakens the coefficient for the momentum premium (from -1.614 to -0.688). We obtain similar results when we use the portfolio based measure of RD.

In summary, a higher world return dispersion is followed by lower market returns, a smaller momentum premium and a higher value premium. The relation between dispersion and the size premium is weak and insignificant across countries. These findings are robust to the exclusion of the US from the panel and the weighting scheme used to calculate world return dispersion.

\section{3. $R D$ as a predictor of market volatility.}

${ }^{18}$ We calculate for each market the monthly market volatility at month $t\left(M V_{t}\right)$ using daily market return $\left(r_{m}\right)$ within the calendar month. Specifically, we calculate monthly market volatility as: $\mathrm{MV}_{\mathrm{t}}=$ $\sqrt{n_{t}} \sqrt{\operatorname{Var}\left(r_{m}\right)}$, where $n_{t}$ is the number of days in month $t$. 
The evidence presented in section 3.2 suggests that RD forecasts changes in future returns. Is RD a predictor of changes in market volatility? We test this hypothesis by estimating the following panel regression using data from the G7 countries:

$$
\begin{aligned}
M V_{t}= & \gamma_{0}+\gamma_{1} R D_{t-1}+\gamma_{2} A C_{t-1}+\gamma_{3} M k t_{t-1}+\gamma_{4} T S_{t-1}+\gamma_{5} d U E_{t-1}+ \\
& \gamma_{6} I N T_{t-1}+\gamma_{7} D Y_{t-1}+\epsilon_{t}
\end{aligned}
$$

where $M V_{t}$ is the 3-month moving average of market volatility in month $\mathrm{t}$ and the other variables as described in the previous section. The results presented in table 5 suggest that return dispersion is an important predictor of future market volatility. The full panel results suggest a positive and statistically significant relation between world RD and world market volatility. The results are robust to the exclusion of the US from the full panel of countries. The evidence are pervasive across countries with positive and significant estimates for all countries in the sample. Our findings are consistent with the evidence presented in Stivers (2003) and Connolly and Stivers (2006) who find a positive relation between US monthly and daily return dispersion and stock market volatility. Our findings add to the existing evidence using data from the G7 countries and are consistent with the hypothesis that RD is a state variable proxying for changes in future expected returns and aggregate volatility.

\section{Sub-sample Analysis and Alternative Return Dispersion Measures}

In this section we examine the robustness of the evidence on the predictive ability of world RD for the economy and factor returns over sub-samples and alternative measures of return dispersion. 
We split the sample in two periods: 1980-1996 and 1997-2012. Table 6 shows estimation results for the economy proxies, factor returns and market volatility in the two sub-samples. In the first sub-sample the relation between the business cycle dummy and $\mathrm{RD}$ is positive but statistically significant only for the equally weighted measure of dispersion. The relation between the ADS business conditions index and RD is negative and consistent with the full sample results and statistically significant for the equally weighted measure of $\mathrm{RD}$. For unemployment, the relation is positive and statistically significant only for the equally weighted measure of RD. In the second period, the estimates are consistent with the full sample estimates and both world RD measures (with the exception of the ADS business condition index and equally weighted world RD where the coefficient is negative but not statistically significant).

Panel B shows coefficient estimates for world RD for the market and the three factor premia. For the market portfolio the relation between word RD and market returns is consistently negative and statistically significant across both sub-period and measures of dispersion. For the value premium the coefficient estimates are positive in both periods but statistically significant only in the later period. For the momentum premium, the coefficient of world RD is consistently negative and statistically significant across both periods and measures of world RD.

Overall the evidence for both economic and factor returns suggest consistent but weaker relationships in the first sub-period compared with the second sub-sample. The stronger relationships observed in the later period are consistent with the increase in the importance of the common factor in country return dispersion measures discussed in section 2. The second sub-period coincides with increased economic and financial 
integration and increased relevance of a common factor driving economic growth and real interest rates. ${ }^{19}$

In table 7 we show estimation results using alternative measures of return dispersion. The first set of alternative measures of return dispersion are the equally and capitalization weighted measures of country return dispersions, based on monthly individual stock return data. For the second alternative of world measure we follow Stivers and Sun (2010) and Maio (2014) to create a world dispersion measure based on the return dispersion of 100 portfolios sorted on size and book to market using all stocks in our database. Portfolio level return dispersion may be less noisy than firm level return dispersion. Using portfolios than individual stocks reduces the influence of extreme individual returns. Stivers and Sun (2010) note that portfolio level returns dispersion performs similarly but generally better than firm level dispersion metrics.

The results presented in tables 3,4 , and 5 are robust to the use of individual country return dispersion measures. Coefficient estimates in table 7, panels A, B and C (columns 2 and 4), are similar to estimated based on world RD for the economic variables, market return and factor premia and market volatility. The lower explanatory power of regressions and the generally lower t-statistics for the coefficient estimates using country RD measures for both the economy and premia sets of variables suggests that world $\mathrm{RD}$ is a better measure of return dispersion. Results from using a world dispersion measure based on portfolio rather than individual stock returns are in columns 3 and 5 of table 7 . Consistent with evidence based on the world RD measure based on individual stocks, a relatively higher portfolio RD indicates a higher probability that the

\footnotetext{
${ }^{19}$ See Perspectives on global real interest rates, IMF 2014.
} 
economy will be in recession, is negatively related with the ADS business conditions index and positively associated with unemployment. A higher RD is followed by a positive value premium, a negative momentum premium, a lower market return and higher future market volatility. Comparing the predictive power of portfolio based RD with stock based world RD we find that it performs marginally better (has more predictive power) for market returns and the factor premia but has lower power in the prediction of economic variables and market volatility.

Are the results presented earlier sensitive to the exclusion of US stocks from the world RD measures? To answer this question we construct equally and capitalization weighted world RD measures using data from the six remaining countries. Table 8 shows that the predictive ability of $\mathrm{RD}$ for the economy, risk premia and market volatility is robust to measures of RD that exclude US stocks.

\section{Return Dispersion and Idiosyncratic Volatility}

Stivers (2003) and Garcia, Mantilla-Garcia and Martellini (2013) show that return dispersion is related to idiosyncratic and market volatility. Stivers (2003) show that $C S V_{\mathrm{t}} \cong \sigma_{\beta}^{2}\left(r_{m t}-r_{f t}\right)^{2}+\sigma_{t}^{2}$, where $\sigma_{\beta}^{2}$ is the cross-sectional variance of betas and $\sigma_{t}^{2}$ is the idiosyncratic variance. Garcia, Mantilla-Garcia and Martellini (2013) generalize the formula and prove that:

$$
\mathrm{E}\left(\mathrm{CSV}_{\mathrm{t}}\right)=\sum_{\mathrm{i}=1}^{\mathrm{N}} \mathrm{w}_{\mathrm{it}} \sigma_{\epsilon_{i t}}^{2}-\sum_{\mathrm{i}=1}^{\mathrm{N}} \mathrm{w}_{\mathrm{it}}^{2} \sigma_{\epsilon_{i t}}^{2}+\mathrm{E}\left(F_{t}^{2} \operatorname{CSV}_{\mathrm{t}}^{\beta}\right)
$$


where $\operatorname{CSV}_{\mathrm{t}}^{\beta}$ is the cross sectional variance of stock betas, $\sigma_{\epsilon_{i t}}^{2}$ is the specific variance of stock $\mathrm{i}$, and $F_{t}^{2}$ is the square return of the factors at time $\mathrm{t}$.

We calculate monthly idiosyncratic volatilities (IV) in month t as:

$$
\mathrm{IV}_{\mathrm{t}}=\sum_{\mathrm{i}=1}^{\mathrm{N}} \mathrm{w}_{\mathrm{i}, \mathrm{t}} \sqrt{\mathrm{n}_{\mathrm{t}}} \sqrt{\operatorname{Var}\left(\varepsilon_{\mathrm{it}}\right)},
$$

where $\mathrm{w}_{\mathrm{it}}$ is either equal to $\frac{1}{N}$ or to the market capitalization weight of stock $\mathrm{i}$ in month $\mathrm{t}-1, \mathrm{n}_{\mathrm{t}}$ is the number of days in month $\mathrm{t}$ and $\varepsilon_{\mathrm{it}}$ is the firm specific return that is estimated every month $t$ from the following regression:

$$
r_{i t}=\alpha_{i}+\beta_{i} r_{m t}+\varepsilon_{i t}
$$

Equation 10 shows that return dispersion is a function of idiosyncratic volatility, the variance of factor returns and the cross sectional variance of stock beta factors. Guo and Savickas (2008) argue that idiosyncratic volatility is a proxy for changes in the investment opportunity set and report evidence based on the G7 countries consistent with the hypothesis that idiosyncratic volatility is a predictor of the market and value premiums.

Garcia, Mantilla-Garcia, and Martellini (2013) show that return dispersion and idiosyncratic risk are highly correlated. In our dataset and for the equally (capitalization) weighted scheme, the average correlation between world, country, and portfolios based return dispersion and idiosyncratic risk are $0.70(0.78), 0.86(0.89)$ and $0.47(0.36)$, respectively. As expected all measures are positively correlated but the world and the portfolio based measures are less correlated with idiosyncratic risk and hence may not 
capture the same economic information. In this section we investigate whether return dispersion conveys incremental information relative to idiosyncratic volatility.

To explore the role of dispersion in the presence of idiosyncratic volatility we reestimate equations 2-9 including idiosyncratic volatility to the list of independent variables. Table 9 shows estimation results for the three equally weighted dispersion measures (results for capitalization weighted dispersion are shown in Table A1 in the appendix). For the main measure of dispersion, world RD (columns 2-3), the estimated coefficients of dispersion for the business cycle variable and unemployment remain statistically significant in the presence of idiosyncratic volatility. For the ADS business conditions index, the coefficient for world RD is insignificant. For the country-based measures of dispersion (columns 4-5) the coefficient for the unemployment rate is statistically significant as is the coefficient for the ADS business conditions index but with the wrong sign. The change in sign when both variables are included in the regression is indicative of multicollinearity (the average correlation across countries for country based dispersion and idiosyncratic volatility is 0.86 ). When we use the portfolio based world dispersion (columns 6-7) the coefficients for dispersion are not statistically different form zero.

The independent role of dispersion becomes clearer when we look at the market return and factor premia evidence. When we use world RD, the coefficient of idiosyncratic volatility is not different from zero for the value and momentum premia and marginally significant, but with the wrong sign, for the market premium. Country-based measures of dispersion also drive out the significance of idiosyncratic volatility. We get much stronger results for the superiority of dispersion when we use the portfolio based 
measure of world dispersion. For the market and value and momentum premia we find strongly significant results for dispersion and insignificant coefficient estimates for idiosyncratic volatility. Portfolio based measures of dispersion have more explanatory power than either world RD or country based dispersion.

The evidence in table 9 suggests that RD has more information than idiosyncratic volatility. This is consistent with equation 10 which shows that RD is the sum of idiosyncratic volatility plus a term equal to the product of market variance times the cross-sectional dispersion of stock betas. From a theoretical perspective, Gomes, Kogan and Zhang (2003) provide a theoretical link between RD, aggregate volatility and the dispersion of stocks betas. In particular, their conditional CAPM suggests that the countercyclical nature of RD is due to the countercyclical behavior of its components: aggregate volatility and the cross-sectional dispersion of stock betas.

Dispersion and idiosyncratic volatility are both significant predictors of future market volatility. The predictive power of regressions that include only dispersion is less than regressions that include both dispersion and idiosyncratic volatility (compare tables 5 and 9) indicating that for predicting market volatility both volatility measures are relevant. The empirical evidence in table 9 suggest that dispersion is a better measure than idiosyncratic volatility for the market, value and momentum premia. For the economic variables the evidence are less clear-cut.

As a final test of the information content of return dispersion we calculate the economic benefits to an investor who uses return dispersion or idiosyncratic volatility to forecast returns and creates dynamically optimal portfolios. We then compare the improvement in Sharpe ratio of return dispersion driven strategies to a dynamic 
investment strategy based on idiosyncratic volatility driven equity premia forecasts and a static buy and hold portfolio of country premia (the market capitalization portfolios of country returns or the three long-short factor portfolios). The evidence, however, should be interpreted with caution given the short period of out-of-sample data available and the effects of estimation error in return and risk forecasts on mean-variance optimization based portfolios (see DeMiguel, Garlappi and Uppal (2009)).

The empirical evidence suggests that using return dispersion generates significant improvements to the Sharpe ratio of the buy and hold portfolio. Compared to idiosyncratic volatility driven forecasts, return dispersion based predictions lead to small but economically significant improvements in the performance of the value and momentum factor timing strategies (details of investment strategy construction and estimation results are given in table $\mathrm{A} 2$ in the appendix).

\section{Conclusions}

Return dispersion is a timely, model free estimation of risk. Academics and practitioners have used return dispersion as a measure of risk and uncertainty and an advance indicator of business conditions. We provide evidence on the ability of RD to predict changes in the investment opportunity set.

We provide strong evidence suggesting that $\mathrm{RD}$ is a good predictor of future economic developments. In particular we find that a relatively higher RD is followed by an increase in unemployment, a higher probability that the economy is in recession.

$\mathrm{RD}$ observed in time t predicts future twelve month market returns, value and momentum premia and market volatility. The results are robust across sub-periods, alternative measures of RD and remain intact when the US is excluded from the data. 
We find that $\mathrm{RD}$ conveys incremental information relative to idiosyncratic volatility. There are two possible explanations for the superiority of RD. First, RD is a better, less noisy market state variable than idiosyncratic volatility. Measures of idiosyncratic volatility require high frequency data which introduce severe biases due to non-synchronous trading and the effect of the bid-ask bounce in trade prices (Han and Lesmond (2011) and Han, Hu and Lesmond (2014)). Microstructure biases could explain the contradictory evidence of a negative relation between RD and future market returns found in this paper and Maio (2014) and the positive relation reported in Garcia, GarciaMantilla and Martellini (2013). Second RD by construction has more information than idiosyncratic volatility. In particular, in addition to idiosyncratic volatility, RD reflects movements in aggregate stock market volatility and the cross section of stock betas, both countercyclical variables with predictive power for future market returns and factor premia. 


\section{References}

Adrian, T., Rosenberg, J., 2008. Stock returns and volatility: pricing the short-run and long-run components of market risk. Journal of Finance 63, 2997-3030.

Ang, A., Piazessi, M., Wei., M., 2006. What does the yield curve tell us about GDP growth?. Journal of Econometrics 131, $359-403$.

Aruoba, S., Diebold, F., Scotti, C., 2009. Real-time measurement of business condition. Journal of Business \& Economic Statistics 27, 417-427.

Bali,T.,Cakici,N.,Levy,H.,2008.A model-independent measure of aggregate idiosyncratic risk. Journal of Empirical Finance 15 , 878-896.

Bansal, R., Yaron, A., 2004. Risks for the long run: A potential resolution of asset pricing puzzles. Journal of Finance 59, 1481-1509.

Bekaert, B., Hodrick, R., Zhang, X., 2012. Aggregate idiosyncratic volatility. Journal of Financial and Quantitative Analysis 47, 1155-1185.

Black, F, 1987. A gold standard with double feedback and near zero reserves. Business Cycles and Equilibrium.

Black, F, 1995. Exploring General Equilibrium, MIT Press.

Bloom, N., 2009. The Impact of uncertainty shocks. Econometrica 77, 623-685.

Bloom, N., Floetotto, M., Jaimovich, N., Saporta-Eksten, I., Terry, S., 2012. Really uncertain business cycles. Working paper, NBER

Britten-Jones, M., Neuberger, A. , Nolte, I., 2011. Improved inference in regression with overlapping observations. Journal of Business Finance \& Accounting 38, 657-683.

Brockman, P., Chung, D. , Perignon, C., 2009. Commonality in liquidity: a global perspective. Journal of Financial and Quantitative Analysis 44, 851-882.

Busse, J., Goyal, A., Wahal, S., 2013. Investing in a global world. Review of Finance, forthcoming.

Campbell, J., 1996. Understanding risk and return. Journal of Political Economy 104, $298-345$. 
Chen Z., Petkova, R., 2012. Does idiosyncratic volatility proxy for risk exposure?. Review of Financial Studies 25, 2745-2787.

Chen, J., 2003. Intertemporal CAPM and the cross-section of stock returns. Working paper, University of California, Davis.

Chen, J., Kannan, P., Loungani, P., Trehan, B., 2011. New evidence on cyclical and structural sources of unemployment. Working paper, IMF

Chen, N., 1991. Financial investment opportunity and the macroeconomy. Journal of Finance 46, $529-554$.

Christie, W., Huang, R., 1995. Following the pied piper: do individual returns herd around the market?. Financial Analysts Journal 51, 31-37.

Connolly, R., Stivers, C., 2006. Information content and other characteristics of the daily cross-sectional dispersion in stock returns. Journal of Empirical Finance 13, 79-112.

Connor, G., Li, S., 2009. Market dispersion and the profitability of hedge funds. Working paper.

DeMiguel, V., Garlappi L., Uppal, R., 2009. Optimal versus Naive Diversification: How Inecient is the 1/N Portfolio Strategy?. The Review of Financial Studies 22, 1915-1953.

Engle, R., Rangel, J., 2008. The spline-GARCH model for low-frequency volatility and its global macroeconomic causes. Review of Financial Studies 21, 1187 -1222.

Estrella, A., Hardouvelis, G. ,1991. The term structure as a predictor of real economic activity. Journal of Finance 46, 555-576.

Fama, E., French, K., 1992. The cross section of expected stock returns. Journal of Finance 47, 427-465.

Fama, E., French, K.,1993. Common risk factors in the returns on stocks and bonds. Journal of Financial Economics 33, 3-56.

Fornari, F., Mele, A., 2009. Financial volatility and economic activity. Working paper.

Fung, W., Hsieh, D., 2004. Hedge fund benchmarks: A risk-based approach. Financial Analysts Journal 60, 65-80. 
Garcia, R., F., Mantilla-Garcia, Martellini, L., 2013. A model-free measure of aggregate idiosyncratic volatility and the prediction of market returns. Forthcoming, Journal of Financial and Quantitative Analysis.

Gomes, J., Kogan, L., Zhang, L., 2003. Equilibrium cross section of returns. Journal of Political Economy 111, 693-732.

Goyal, A., Santa-Clara, P., 2003. Idiosyncratic risk matters! Journal of Finance 58 , 9751008.

Guo, H., Savickas, R. 2008. Average idiosyncratic volatility in G7 countries. Review of Financial Studies 21, 1259-1296.

Han, Y., Lesmond, D. 2011. Liquidity Biases and the Pricing of Cross-sectional Idiosyncratic Volatility. Review of Financial Studies 24, 1590-1629.

Han, Y., Hu, T., Lesmond, D. 2014. Liquidity Biases and the Pricing of Cross-Sectional Idiosyncratic Volatility Around the World. Forthcoming, Journal of Financial and Quantitative Analysis.

Hamilton, J., Lin, G., 1996. Stock market volatility and the business cycle. Journal of Applied Econometrics 11, 573-593.

Harvey, C.R, 1991. The term structure and world economic growth. Journal of Fixed Income 1, 7-19

Hou, K., Karolyi, A., Kho, B., 2011. What factors drive global stock returns?. Review of Financial Studies $24,2527-2574$.

International Monetary Fund, World economic outlook, perspectives on global real interest rates, April 2014.

Ince, O., Porter, R., 2006. Individual equity return data from Thomson Datastream: handle with care!. Journal of Financial Research 29, 463-479.

Lilien, D. M, 1982. Sectoral shifts and cyclical unemployment. Journal of Political Economy 90, 773-93.

Lo, A., MacKinlay, A., 1990. Data-snooping biases in tests of financial asset pricing models. Review of Financial Studies 3, 431-467. 
Loungani, P., Rush, M., Tave, W., 1990. Stock market dispersion and unemployment. Journal of Monetary Economics 25, 367 -388.

Maio, P. F., 2014. Cross-sectional return dispersion and the equity premium. Working Paper, Hanken School of Economics.

Merton, R., 1973. An Intertemporal capital asset pricing model. Econometrica 41, 867887.

Newey, W., West, K., 1987. A simple positive semi-definite, heteroskedasticity and autocorrelation consistent covariance matrix. Econometrica 55, 703-708.

Petersen, M., 2009. Estimating standard errors in finance panel data sets: comparing approaches. Review of Financial Studies 22, 435-480.

Pollet, J.M, Wilson, M., 2010. Average correlation and stock market returns. Journal of Financial Economics 96, 364-380.

Schwert, W., 1989. Margin requirements and stock volatility. Journal of Financial Services Research 3, 153-164.

Silva, H. , Sapra, S., S. Thorley, S., 2001. Return dispersion and active management. Financial Analysts Journal 57, 29-42.

Solnik, B., Roulet, J., 2000. Dispersion as cross-sectional correlation. Financial Analysts Journal, 56 , 54-61.

Stivers, C. T, 2003. Firm-level return dispersion and the future volatility of aggregate stock market returns. Journal of Financial Markets 6, 389-411.

Stivers, C., Sun, L., 2010. Cross-sectional return dispersion and time-variation in value and momentum premia. Journal of Financial and Quantitative Analysis 45, 987- 1014.

Stivers, C., Sun, L., 2013. Market cycles and the performance of relative strength strategies. Financial Management, 263-290.

Stock, J.H., Watson, M.W., 2003. Forecasting output and inflation. Journal of Economic Literature 41, 788 - 829 
Wei, S., Zhang, C., 2005. Idiosyncratic risk does not matter: A re-examination of the relationship between average returns and average volatilities. Journal of Banking and Finance 29, 603-621.

White, H, 1980. A Heteroskedasticity-consistent covariance matrix estimator and a direct test for heteroskedasticity. Econometrica $48,817-838$. 


\section{Table 1. Descriptive Statistics}

This table presents the descriptive statistics of country, world and portfolio based measures of monthly return dispersion. The equally weighted and capitalization-weighted measures of dispersion are shown in Panels A and B, respectively. All measures are calculated as a 3-month average of monthly cross sectional return dispersion. The sample period is from $07 / 31 / 1980$ to $12 / 31 / 2012$.

\begin{tabular}{|c|c|c|c|c|c|c|c|}
\hline \multicolumn{8}{|c|}{ Panel A. Equally Weighted Return Dispersion } \\
\hline & Mean & Median & Max & Min & S.D & Skew & Kurt \\
\hline Canada & 0.1119 & 0.1090 & 0.2568 & 0.0637 & 0.0284 & 1.3014 & 3.5883 \\
\hline France & 0.0809 & 0.0747 & 0.2047 & 0.0494 & 0.0208 & 2.0564 & 7.0789 \\
\hline Germany & 0.0757 & 0.0712 & 0.1868 & 0.0312 & 0.0284 & 1.0662 & 1.0661 \\
\hline Italy & 0.0698 & 0.0653 & 0.1821 & 0.0394 & 0.0207 & 1.9658 & 5.7386 \\
\hline Japan & 0.0758 & 0.0724 & 0.1359 & 0.0445 & 0.0164 & 0.8605 & 0.6537 \\
\hline U.K. & 0.0893 & 0.0873 & 0.2032 & 0.0399 & 0.0233 & 1.4505 & 4.0435 \\
\hline US & 0.0913 & 0.0833 & 0.1958 & 0.0597 & 0.0254 & 1.8458 & 3.5569 \\
\hline World & 0.0964 & 0.0906 & 0.1957 & 0.0644 & 0.0214 & 1.6175 & 3.2384 \\
\hline World 100 Portfolios & 0.0242 & 0.0231 & 0.0714 & 0.0119 & 0.0081 & 2.2866 & 9.2123 \\
\hline \multicolumn{8}{|c|}{ Panel B. Capitalization Weighted Return Dispersion } \\
\hline & Mean & Median & Max & Min & S.D & Skew & Kurt \\
\hline Canada & 0.0748 & 0.0703 & 0.1708 & 0.0473 & 0.0183 & 1.8456 & 4.4345 \\
\hline France & 0.0659 & 0.0624 & 0.1440 & 0.0370 & 0.0167 & 1.4112 & 2.8460 \\
\hline Germany & 0.0599 & 0.0538 & 0.1339 & 0.0271 & 0.0209 & 1.2318 & 1.2589 \\
\hline Italy & 0.0590 & 0.0547 & 0.1916 & 0.0315 & 0.0210 & 2.4075 & 9.2552 \\
\hline Japan & 0.0697 & 0.0666 & 0.1345 & 0.0353 & 0.0180 & 0.9951 & 1.2546 \\
\hline U.K. & 0.0664 & 0.0628 & 0.1400 & 0.0402 & 0.0172 & 1.6516 & 3.5922 \\
\hline US & 0.0703 & 0.0634 & 0.1688 & 0.0427 & 0.0204 & 2.1263 & 5.2494 \\
\hline World & 0.0764 & 0.0714 & 0.1623 & 0.0508 & 0.0184 & 1.5754 & 3.1301 \\
\hline World 100 Portfolios & 0.0204 & 0.0194 & 0.0515 & 0.0082 & 0.0071 & 1.0985 & 1.8849 \\
\hline
\end{tabular}




\section{Table 2. Commonality in Country Return Dispersion}

Panel A presents the correlations of the equally and capitalization weighted return dispersion across the G7 countries, the world and portfolio based measures of return dispersion. The sample period is from 07/31/1980 to 12/31/2012.

\begin{tabular}{|c|c|c|c|c|c|c|c|}
\hline \multicolumn{8}{|c|}{ Panel A. Correlation of Different Measures of Return Dispersion } \\
\hline \multicolumn{8}{|c|}{ Equally Weighted Return Dispersion } \\
\hline & Canada & France & Germany & Italy & Japan & U.K. & US \\
\hline France & 0.67 & & & & & & \\
\hline Germany & 0.62 & 0.82 & & & & & \\
\hline Italy & 0.38 & 0.50 & 0.29 & & & & \\
\hline Japan & 0.42 & 0.53 & 0.48 & 0.28 & & & \\
\hline UK & 0.66 & 0.76 & 0.80 & 0.47 & 0.52 & & \\
\hline US & 0.79 & 0.79 & 0.77 & 0.46 & 0.54 & 0.76 & \\
\hline World & 0.83 & 0.82 & 0.76 & 0.49 & 0.70 & 0.82 & 0.93 \\
\hline World ex US & 0.82 & 0.81 & 0.74 & 0.51 & 0.76 & 0.84 & 0.83 \\
\hline World 100 Portfolios & 0.50 & 0.58 & 0.37 & 0.51 & 0.55 & 0.49 & 0.64 \\
\hline \multicolumn{8}{|c|}{ Capitalization Weighted Return Dispersion } \\
\hline & Canada & France & Germany & Italy & Japan & U.K. & US \\
\hline France & 0.71 & & & & & & \\
\hline Germany & 0.70 & 0.75 & & & & & \\
\hline Italy & 0.62 & 0.67 & 0.47 & & & & \\
\hline Japan & 0.62 & 0.62 & 0.57 & 0.43 & & & \\
\hline UK & 0.85 & 0.80 & 0.77 & 0.69 & 0.68 & & \\
\hline US & 0.89 & 0.76 & 0.78 & 0.62 & 0.61 & 0.86 & \\
\hline World & 0.83 & 0.79 & 0.71 & 0.62 & 0.80 & 0.85 & 0.89 \\
\hline World ex US & 0.74 & 0.77 & 0.66 & 0.61 & 0.89 & 0.83 & 0.73 \\
\hline World 100 Portfolios & 0.35 & 0.50 & 0.20 & 0.36 & 0.51 & 0.43 & 0.41 \\
\hline
\end{tabular}


Table 3. Return Dispersion and Future Economic Activity

This table presents evidence on the predictive ability of world return dispersion (equally or capitalization weighted) for economic activity. Economic activity is measured as (a) a dummy variable that takes the value of 1 when the economy is in recession and 0 otherwise, (b) the $A D S$ business condition index $\left(A D S_{t}\right)$ and (c) the change in unemployment rate $\left(d U E_{t}\right)$. Predictor variables include world return dispersion and as control variables average correlation, market return, term spread, the growth in unemployment rate, market dividend yield and the short-term nominal interest rate; for the ADS business condition index we also include a lag of the ADS index as control variable. In rows 1-3 we estimate a panel regression model with the G7 countries. In rows 4-6 we exclude the US from the full panel of countries. In rows 7-21 we estimate a single regression model for each country. The panel model for equations Probit $\left(D_{t}\right), A S_{t}$ and $\operatorname{dUE}_{t}$, uses country dummies and clusters the standard errors by country. For $\mathrm{ADS}_{\mathrm{t}}$ and $\mathrm{dUE}_{\mathrm{t}}$, we also adjust the standard errors using the Newey-West procedure (Newey and West, 1987) modified for use in a panel data set (see Petersen 2009). For the single regression equations we adjust the standard errors using the Newey-West procedure. t-statistics in parentheses and $\overline{\boldsymbol{R}}^{2}$ in brackets, *Denotes significance at the $10 \%$ level, **Denotes significance at the $5 \%$ level, ***Denotes significance at the $1 \%$ level.

\begin{tabular}{|c|c|c|c|c|c|c|}
\hline & \multicolumn{2}{|c|}{ Business Cycle Dummy } & \multicolumn{2}{|c|}{ ADS Business Condition Index } & \multicolumn{2}{|c|}{ Unemployment Rate } \\
\hline & \multicolumn{2}{|c|}{$\operatorname{Probit}\left(D_{t}\right)$} & \multicolumn{2}{|c|}{$A D S_{t}$} & \multicolumn{2}{|c|}{$d U E_{t}$} \\
\hline & $R D_{\text {world } t-1}^{e w}$ & $R D_{\text {world } t-1}^{c w}$ & $R D_{\text {world } t-1}^{e w}$ & $R D_{\text {world } t-1}^{c w}$ & $R D_{\text {world } t-1}^{e w}$ & $R D_{\text {world } t-1}^{c w}$ \\
\hline \multirow[t]{3}{*}{ PANEL } & $17.240 * * *$ & $14.630 * * *$ & $-1.007^{*}$ & $-1.007 *$ & $0.200 * * *$ & $0.173 * * *$ \\
\hline & $(3.940)$ & $(3.055)$ & $(-1.825)$ & $(-1.882)$ & $(5.319)$ & $(4.425)$ \\
\hline & {$[27.10 \%]$} & {$[25.30 \%]$} & {$[76.00 \%]$} & {$[75.90 \%]$} & {$[7.89 \%]$} & {$[6.99 \%]$} \\
\hline \multirow[t]{3}{*}{ PANEL EXCL.US } & $15.670 * * *$ & $12.750 * *$ & -0.533 & -0.580 & $0.172 * * *$ & $0.155^{* * *}$ \\
\hline & $(3.400)$ & $(2.440)$ & $(-0.851)$ & $(-0.942)$ & $(4.225)$ & $(3.699)$ \\
\hline & {$[24.30 \%]$} & {$[22.60 \%]$} & {$[78.70 \%]$} & {$[78.70 \%]$} & {$[9.59 \%]$} & {$[9.03 \%]$} \\
\hline \multirow[t]{3}{*}{ CANADA } & $30.440 * * *$ & $21.910 * * *$ & 0.238 & 0.187 & $0.296 * * *$ & $0.273^{* * *}$ \\
\hline & $(7.344)$ & $(4.429)$ & $(0.276)$ & $(0.211)$ & $(4.432)$ & $(3.948)$ \\
\hline & [53.10\%] & [47.90\%] & {$[96.60 \%]$} & {$[96.60 \%]$} & {$[15.10 \%]$} & [13.60\%] \\
\hline \multirow[t]{3}{*}{ GERMANY } & $12.20 * * *$ & 1.619 & 0.637 & 0.335 & 0.004 & -0.015 \\
\hline & $(2.859)$ & $(0.355)$ & $(0.446)$ & $(0.241)$ & $(0.071)$ & $(-0.250)$ \\
\hline & [60.90\%] & [59.60\%] & [85.60\%] & [85.60\%] & [14.70\%] & [14.70\%] \\
\hline \multirow[t]{3}{*}{ JAPAN } & $18.090 * * *$ & $19.500 * * *$ & -0.454 & -0.885 & $0.235^{* *}$ & $0.250 * *$ \\
\hline & (4.040) & $(4.262)$ & $(-0.482)$ & $(-0.968)$ & $(2.535)$ & $(2.538)$ \\
\hline & {$[25.60 \%]$} & [25.40\%] & [90.70\%] & [90.70\%] & [3.26\%] & [3.20\%] \\
\hline \multirow[t]{3}{*}{ UK } & -10.680 & -9.912 & -1.081 & -0.841 & $0.086^{*}$ & $0.083^{*}$ \\
\hline & $(-1.470)$ & $(-1.125)$ & $(-0.762)$ & $(-0.562)$ & (1.694) & (1.728) \\
\hline & [59.00\%] & [58.90\%] & [48.40\%] & [48.30\%] & [45.10\%] & [45.00\%] \\
\hline \multirow[t]{3}{*}{ US } & $28.950 * * *$ & $26.210 * * *$ & $-2.390 *$ & $-2.552 * *$ & $0.341 * * *$ & $0.279 * * *$ \\
\hline & (5.491) & (5.189) & $(-1.874)$ & $(-2.274)$ & (3.709) & $(2.928)$ \\
\hline & {$[45.70 \%]$} & [43.10\%] & [64.20\%] & [64.30\%] & [7.30\%] & [5.09\%] \\
\hline
\end{tabular}




\section{Table 4. Forecasting Market and Factor Premia Using Return Dispersion}

This table presents evidence on the predictive ability of equally and capitalization weighted world dispersion for twelve month market returns $\left(M r k t_{t+11}\right)$ and the value $\left(H M L_{t+11}\right)$, size $\left(S M B_{t+11}\right)$, and momentum $\left(M O M_{t+11}\right)$ premia. The predictive regressions include world return dispersion and as control variables the market dividend yield, the short-term nominal interest rate and the average correlation. In rows 1-3 we estimate a panel regression model with the G7 countries. In rows 4-6 we exclude the US from the full panel of countries. In rows 7-27 we estimate a single regression model for each country. The panel model uses country dummies and clusters the standard errors by country. We also adjust the standard errors using the Newey-West procedure (Newey and West, 1987) modified for use in a panel data set (see Petersen 2009). Newey-West t-statistics are adjusted for overlapping using the methodology of Britten-Jones, Neuberger and Nolte (2011). For the single regression equations we adjust the standard errors using the Newey-West procedure. t-statistics in parentheses and $\overline{\boldsymbol{R}}^{2}$ in brackets, $*$ Denotes significance at the $10 \%$ level, **Denotes significance at the 5\% level, ***Denotes significance at the $1 \%$ level.

\begin{tabular}{|c|c|c|c|c|c|c|c|c|}
\hline & \multicolumn{2}{|c|}{ Mrkt $_{t+11}$} & \multicolumn{2}{|c|}{$H M L_{t+11}$} & \multicolumn{2}{|c|}{$S M B_{t+11}$} & \multicolumn{2}{|c|}{$\operatorname{MOM}_{t+11}$} \\
\hline & $R D_{w o r l d}^{e w}{ }_{t-1}$ & $R D_{\text {world }}^{c w-1}$ & $R D_{\text {world }}^{e w-1}$ & $R D_{w o r l d}^{c w}{ }_{t-1}$ & $R D_{\text {world }}^{e w-1}$ & $R D_{w o r l d}^{c w}{ }_{t-1}$ & $R D_{w o r l d}^{e w-1}$ & $R D_{\text {world } t-1}^{c w}$ \\
\hline \multirow[t]{3}{*}{ PANEL } & $-1.741 * * *$ & $-2.426 * * *$ & $1.650 * * *$ & $1.608 * * *$ & -0.067 & 0.134 & $-1.800 * * *$ & $-2.188 * * *$ \\
\hline & $(-3.097)$ & $(-4.161)$ & $(4.021)$ & $(3.327)$ & $(-0.238)$ & $(0.425)$ & $(-3.674)$ & $(-4.197)$ \\
\hline & [1.69\%] & [1.87\%] & [3.97\%] & [3.72\%] & {$[0.52 \%]$} & [0.53\%] & [4.32\%] & [4.53\%] \\
\hline \multirow[t]{3}{*}{ PANEL EXCL.US } & $-1.771 * * *$ & $-2.496 * * *$ & $1.523 * * *$ & $1.477 * * *$ & -0.352 & -0.102 & $-1.681 * * *$ & $-2.080 * * *$ \\
\hline & $(-2.834)$ & $(-3.847)$ & $(3.458)$ & $(2.869)$ & $(-1.229)$ & $(-0.320)$ & $(-3.213)$ & $(-3.734)$ \\
\hline & [1.40\%] & [1.58\%] & [4.01\%] & [3.81\%] & [0.64\%] & [0.61\%] & [4.47\%] & [4.67\%] \\
\hline \multirow[t]{3}{*}{ CANADA } & -0.338 & -0.818 & $2.136^{*}$ & $2.342^{*}$ & 0.118 & -0.250 & $-2.248^{*}$ & $-3.231 * *$ \\
\hline & $(-0.247)$ & $(-0.531)$ & $(1.805)$ & $(1.706)$ & $(0.150)$ & $(-0.295)$ & $(-1.747)$ & $(-2.462)$ \\
\hline & {$[2.40 \%]$} & {$[2.43 \%]$} & {$[5.41 \%]$} & {$[5.47 \%]$} & {$[1.79 \%]$} & {$[1.82 \%]$} & {$[7.93 \%]$} & {$[8.86 \%]$} \\
\hline \multirow[t]{2}{*}{ FRANCE } & -1.907 & $-3.013 * *$ & $2.519 * *$ & $2.544^{*}$ & -0.577 & -0.225 & -2.089 & -2.299 \\
\hline & {$[1.00 \%]$} & {$[1.35 \%]$} & {$[1.91 \%]$} & {$[1.63 \%]$} & {$[-1.07 \%]$} & {$[-1.17 \%]$} & {$[6.03 \%]$} & {$[6.08 \%]$} \\
\hline \multirow[t]{3}{*}{ GERMANY } & $-2.811 * *$ & $-3.788 * * *$ & $2.443 * *$ & $2.617^{*}$ & -0.328 & -0.338 & -0.429 & -0.558 \\
\hline & $(-2.253)$ & $(-3.066)$ & $(2.012)$ & $(1.735)$ & $(-0.528)$ & $(-0.484)$ & $(-0.329)$ & $(-0.380)$ \\
\hline & {$[1.88 \%]$} & {$[2.20 \%]$} & [8.60\%] & [8.49\%] & [1.29\%] & [1.29\%] & {$[2.39 \%]$} & {$[2.41 \%]$} \\
\hline \multirow[t]{3}{*}{ ITALY } & $-3.003 * *$ & $-3.666 * *$ & 0.765 & 0.643 & -1.023 & -0.373 & $-2.746 * * *$ & $-2.653 * *$ \\
\hline & $(-1.990)$ & $(-2.431)$ & $(1.202)$ & $(0.901)$ & $(-1.479)$ & $(-0.581)$ & $(-2.616)$ & $(-2.292)$ \\
\hline & {$[0.58 \%]$} & {$[0.77 \%]$} & [3.32\%] & [3.31\%] & {$[1.42 \%]$} & {$[1.22 \%]$} & [4.62\%] & {$[4.41 \%]$} \\
\hline \multirow[t]{3}{*}{ JAPAN } & -0.970 & -0.943 & 0.560 & 0.376 & -0.063 & 0.054 & -1.485 & -1.783 \\
\hline & $(-0.631)$ & $(-0.515)$ & $(0.783)$ & $(0.420)$ & $(-0.094)$ & $(-0.071)$ & $(-1.276)$ & $(-1.397)$ \\
\hline & {$[0.45 \%]$} & {$[0.43 \%]$} & [6.68\%] & [6.58\%] & {$[-0.56 \%]$} & {$[-0.55 \%]$} & {$[-0.52 \%]$} & {$[-0.29 \%]$} \\
\hline \multirow[t]{2}{*}{ UK } & -1.420 & -1.758 & 0.530 & 0.678 & 0.292 & 0.975 & -1.640 & $-2.175^{*}$ \\
\hline & $(-1.345)$ & $(-1.491)$ & $(0.792)$ & $(0.955)$ & $(0.422)$ & $(1.231)$ & $(-1.526)$ & $(-1.880)$ \\
\hline \multirow{2}{*}{ US } & $(-0.905)$ & $(-1.319)$ & $(2.492)$ & $(2.061)$ & $(2.035)$ & (1.772) & $(-1.776)$ & $(-2.089)$ \\
\hline & [4.28\%] & {$[4.42 \%]$} & [3.31\%] & [2.74\%] & {$[0.53 \%]$} & {$[0.29 \%]$} & [2.69\%] & [3.14\%] \\
\hline
\end{tabular}




\section{Table 5. Forecasting Market Volatility Using Return Dispersion $(R D)$}

This table presents evidence on the predictive ability of equally and capitalization weighted world return dispersion for market volatility $\left(M V_{t}\right)$. The predictive regressions include world return dispersion and as control variables the market dividend yield, the short-term nominal interest rate and average correlation. In rows $1-3$ we estimate a panel model with the G7 countries. In rows 4-6 we exclude the US from the full panel of countries. In rows 7-21 we estimate a single regression model for each country. The panel model uses country dummies and clusters the standard errors by country. We also adjust the standard errors using the Newey-West procedure (Newey and West, 1987) modified for use in a panel data set (see Petersen, 2009). For the single regression equations we adjust the standard errors using the Newey-West procedure. t-statistics in parentheses and $\overline{\boldsymbol{R}}^{2}$ in brackets, *Denotes significance at the $10 \%$ level, **Denotes significance at the 5\% level, ***Denotes significance at the $1 \%$ level.

\begin{tabular}{|c|c|c|}
\hline \multicolumn{3}{|c|}{$M V_{t}$} \\
\hline & $R D_{\text {world }}^{e w-1}$ & $R D_{\text {world }}^{c w-1}$ \\
\hline \multirow[t]{3}{*}{ PANEL } & $0.588 * * *$ & $0.675 * * *$ \\
\hline & $(15.910)$ & $(15.250)$ \\
\hline & {$[58.50 \%]$} & {$[60.80 \%]$} \\
\hline \multirow[t]{3}{*}{ PANEL EXCL.US } & $0.582 * * *$ & $0.670 * * *$ \\
\hline & (13.640) & $(13.060)$ \\
\hline & {$[55.80 \%]$} & {$[58.30 \%]$} \\
\hline \multirow[t]{3}{*}{ CANADA } & $0.701 * * *$ & $0.817 * * *$ \\
\hline & $(6.809)$ & $(6.839)$ \\
\hline & {$[65.00 \%]$} & {$[68.30 \%]$} \\
\hline \multirow[t]{3}{*}{ GERMANY } & $0.612 * * *$ & $0.690 * * *$ \\
\hline & $(8.579)$ & $(7.924)$ \\
\hline & {$[54.10 \%]$} & {$[55.90 \%]$} \\
\hline \multirow[t]{3}{*}{ JAPAN } & $0.499 * * *$ & $0.584 * * *$ \\
\hline & $(7.890)$ & $(7.396)$ \\
\hline & {$[53.40 \%]$} & {$[57.00 \%]$} \\
\hline \multirow[t]{3}{*}{ UK } & $0.522 * * *$ & $0.603 * * *$ \\
\hline & $(9.761)$ & $(9.131)$ \\
\hline & [61.90\%] & {$[65.20 \%]$} \\
\hline \multirow[t]{3}{*}{ US } & $0.545 * * *$ & $0.622 * * *$ \\
\hline & $(7.989)$ & $(7.813)$ \\
\hline & {$[68.80 \%]$} & {$[71.20 \%]$} \\
\hline
\end{tabular}




\section{Table 6. The Predictive Ability of World Return Dispersion: Sub-period Analysis}

This table presents panel regressions estimates of the predictive ability of equally or capitalization weighted world return dispersion for real economic activity (Panel A), market return and factor premia (Panel B) and market volatility (Panel C) for two sub-periods, 1980-1996 and 1997-2012. In Panel A, economic activity is measured as (a) a dummy variable that takes the value of 1 when the economy is in recession and 0 otherwise (b) the $A D S$ business condition index $\left(A D S_{t}\right)$ and (c) the change in unemployment rate $\left(d U E_{t}\right)$. In Panel B the dependent variables are the twelve month market returns $\left(M r k t_{t+11}\right)$, the value $\left(H M L_{t+11}\right)$, size $\left(S M B_{t+11}\right)$, or momentum $\left(M O M_{t+11}\right)$ premia. In Panel C the dependent variable is the market volatility $(M V)_{t}$. In Panels A and C predictor variables include world return dispersion, and as control variables the average correlation, market return, term spread, the growth in unemployment rate, dividend yield and the short-term nominal interest rate; for the ADS business condition index we also include a lag of the ADS index as control variable. In Panel B predictor variables include world return dispersion, and as control variables the average correlation, dividend yield and short-term nominal interest rate. The panel model for all equations uses country dummies and clusters the standard errors by country. For all equations except for the Probit $\left(D_{t}\right)$ we also adjust the standard errors using the Newey-West procedure (Newey and West, 1987) modified for use in a panel data set (see Petersen 2009). For the equations in Panel B Newey-West t-statistics are adjusted for overlapping using the methodology of Britten-Jones, Neuberger and Nolte (2011). t-statistics in parentheses and $\overline{\boldsymbol{R}}^{2}$ in brackets, *Denotes significance at the $10 \%$ level, $* *$ Denotes significance at the $5 \%$ level, $* * *$ Denotes significance at the $1 \%$ level.

\begin{tabular}{|c|c|c|c|c|}
\hline & \multicolumn{2}{|c|}{$R D_{\text {world } t-1}^{\text {ew }}$} & \multicolumn{2}{|c|}{$R D_{\text {world } t-1}^{c w}$} \\
\hline Period & 1980-1996 & 1997-2012 & 1980-1996 & 1997-2012 \\
\hline \multicolumn{5}{|c|}{ Panel A. Return Dispersion and Future Economic Activity } \\
\hline \multirow[t]{3}{*}{$\operatorname{Probit}\left(D_{t}\right)$} & $37.360 * * *$ & $14.410 * * *$ & 2.972 & $17.850 * * *$ \\
\hline & $(5.291)$ & $(6.678)$ & $(0.435)$ & $(5.129)$ \\
\hline & [46.20\%] & [27.30\%] & [40.09\%] & [28.20\%] \\
\hline \multirow[t]{3}{*}{$A D S_{t}$} & $-2.172 *$ & -0.842 & 0.164 & $-1.425 * *$ \\
\hline & $(-1.728)$ & $(-1.381)$ & $(0.126)$ & $(-2.277)$ \\
\hline & {$[69.60 \%]$} & {$[82.50 \%]$} & {$[69.50 \%]$} & [82.60\%] \\
\hline \multirow[t]{3}{*}{$d U E_{t}$} & $0.224 * *$ & $0.211 * * *$ & 0.047 & $0.220 * * *$ \\
\hline & $(2.580)$ & $(4.686)$ & $(0.600)$ & $(4.667)$ \\
\hline & {$[9.71 \%]$} & {$[9.62 \%]$} & {$[10.10 \%]$} & [9.29\%] \\
\hline \multicolumn{5}{|c|}{ Panel B. Forecasting Market and Factor Premia using Return Dispersion } \\
\hline \multirow[t]{3}{*}{$M r k t_{t+11}$} & $-2.188 * *$ & $-1.164 *$ & $-2.456 * *$ & $-1.936 * * *$ \\
\hline & $(-2.365)$ & $(-1.809)$ & $(-2.201)$ & $(-2.777)$ \\
\hline & [2.53\%] & {$[0.79 \%]$} & [2.63\%] & {$[1.02 \%]$} \\
\hline \multirow[t]{3}{*}{$H M L_{t+11}$} & 0.565 & $2.047 * * *$ & 0.330 & $2.052 * * *$ \\
\hline & $(1.216)$ & $(4.751)$ & (0.694) & (3.868) \\
\hline & [2.15\%] & [4.91\%] & [2.11\%] & [4.55\%] \\
\hline \multirow[t]{3}{*}{$S M B_{t+11}$} & -0.347 & 0.269 & 0.401 & 0.214 \\
\hline & $(-0.584)$ & $(0.886)$ & $(0.749)$ & $(0.600)$ \\
\hline & {$[0.27 \%]$} & {$[0.78 \%]$} & {$[0.29 \%]$} & {$[0.76 \%]$} \\
\hline \multirow[t]{3}{*}{$M O M_{t+11}$} & $-1.541 * *$ & $-2.451 * * *$ & $-2.262 * * *$ & $-2.651 * * *$ \\
\hline & $(-2.303)$ & $(-4.437)$ & $(-3.766)$ & $(-4.286)$ \\
\hline & {$[5.62 \%]$} & {$[4.54 \%]$} & {$[6.28 \%]$} & [4.38\%] \\
\hline \multicolumn{5}{|c|}{ Panel C. Forecasting Market Volatility using Return Dispersion } \\
\hline \multirow[t]{3}{*}{$M V_{t}$} & $0.425 * * *$ & $0.641 * * *$ & $0.360 * * *$ & $0.739 * * *$ \\
\hline & $(7.059)$ & $(17.790)$ & $(7.213)$ & $(17.840)$ \\
\hline & {$[57.50 \%]$} & {$[65.40 \%]$} & {$[55.10 \%]$} & {$[68.70 \%]$} \\
\hline
\end{tabular}


Table 7. The Predictive Ability of World Return Dispersion: Robustness to Alternative Measures of Return Dispersion

This table presents panel regressions estimates of the predictive ability of alternative measures of return dispersion for real economic activity (Panel A), market return and factor premia (Panel B) and market volatility (Panel C). In columns 2 and 3 we present the equally weighted country $\left(R D_{\text {country }}^{e w}\right)$, and world portfolio $\left(R D_{\text {portfolio }}^{\text {ew }}\right)$ based measures of return dispersion. In columns 4 and 5 the capitalization weighted country $\left(R D_{\text {country }}^{c w}\right)$ and world portfolio $\left(R D_{\text {portfolio }}^{c w}\right)$ measures of dispersion. In Panel A, economic activity is measured as (a) a dummy variable that takes the value of 1 when the economy is in recession and 0 otherwise (b) the $A D S$ business condition index $\left(A D S_{t}\right)$ and (c) the change in unemployment rate $\left(d U E_{t}\right)$. In Panel B the dependent variables are the twelve month market returns $\left(M r k t_{t+11}\right)$, the value $\left(H M L_{t+11}\right)$, size $\left(S M B_{t+11}\right)$, or momentum $\left(M O M_{t+11}\right)$ premia. In Panel $\mathrm{C}$ the dependent variable is the market volatility $(M V)_{t}$. In Panels $\mathrm{A}$ and $\mathrm{C}$ predictor variables include world return dispersion and as control variables the average correlation, market return, term spread, the growth in unemployment rate, dividend yield and the short-term nominal interest rate; for the ADS business condition index we also include a lag of the ADS index as control variable. In Panel B predictor variables include world return dispersion, and as control variables the average correlation, dividend yield and short-term nominal interest rate. The panel model for all equations uses country dummies and clusters the standard errors by country. For all equations except for the Probit $\left(D_{t}\right)$ we also adjust the standard errors using the Newey-West procedure (Newey and West, 1987) modified for use in a panel data set (see Petersen 2009). For the equations in Panel B Newey-West t-statistics are adjusted for overlapping using the methodology of Britten-Jones, Neuberger and Nolte (2011). t-statistics in parentheses and $\overline{\boldsymbol{R}}^{2}$ in brackets, *Denotes significance at the $10 \%$ level, **Denotes significance at the $5 \%$ level, ***Denotes significance at the $1 \%$ level.

\begin{tabular}{|c|c|c|c|c|}
\hline Measures & $R_{\text {country }}^{\text {ew-1 }}$ & $R_{p_{\text {ortfolio }}}^{\text {ew }}{ }_{-1}$ & $R D_{\text {country }}^{c w}{ }_{t-1}$ & $R D_{\text {portfolio }}^{c w-1}$ \\
\hline \multicolumn{5}{|c|}{ Panel A. Return Dispersion and Future Economic Activity } \\
\hline \multirow[t]{3}{*}{$\operatorname{Probit}\left(D_{t}\right)$} & $15.820 * * *$ & $26.750 * * *$ & $10.730 * * *$ & $21.280 * * *$ \\
\hline & $(5.576)$ & $(6.020)$ & $(3.000)$ & $(2.588)$ \\
\hline & {$[26.80 \%]$} & {$[23.90 \%]$} & {$[24.20 \%]$} & {$[23.00 \%]$} \\
\hline \multirow[t]{3}{*}{$A D S_{t}$} & $-0.864 * *$ & $-2.262 * *$ & $-1.026 *$ & 0.369 \\
\hline & $(-2.023)$ & $(-2.105)$ & $(-1.771)$ & $(0.261)$ \\
\hline & [75.90\%] & {$[76.20 \%]$} & [75.90\%] & {$[76.10 \%]$} \\
\hline \multirow[t]{3}{*}{$d U E_{t}$} & $0.177 * * *$ & $0.284 * * *$ & $0.167 * * *$ & $0.186 *$ \\
\hline & $(5.412)$ & $(3.246)$ & $(4.263)$ & $(1.944)$ \\
\hline & {$[7.74 \%]$} & {$[5.87 \%]$} & {$[6.90 \%]$} & {$[5.28 \%]$} \\
\hline \multicolumn{5}{|c|}{ Panel B. Forecasting Market and Factor Premia using Return Dispersion } \\
\hline \multirow[t]{3}{*}{$\operatorname{Mrkt}_{t+11}$} & -0.611 & $-5.596 * * *$ & $-1.249 *$ & $-5.057 * * *$ \\
\hline & $(-1.065)$ & $(-5.390)$ & $(-1.891)$ & $(-3.362)$ \\
\hline & {$[1.43 \%]$} & {$[2.12 \%]$} & {$[1.52 \%]$} & {$[1.86 \%]$} \\
\hline \multirow[t]{3}{*}{$H M L_{t+11}$} & $1.342 * * *$ & $4.409 * * *$ & $1.527 * * *$ & $2.688 * * *$ \\
\hline & $(3.543)$ & $(5.163)$ & $(3.204)$ & $(3.008)$ \\
\hline & {$[3.82 \%]$} & {$[4.55 \%]$} & {$[3.74 \%]$} & {$[3.46 \%]$} \\
\hline \multirow[t]{3}{*}{$S M B_{t+11}$} & 0.134 & 0.209 & 0.177 & $1.640 * *$ \\
\hline & $(0.490)$ & $(0.338)$ & $(0.538)$ & $(2.362)$ \\
\hline & {$[0.53 \%]$} & {$[0.52 \%]$} & {$[0.54 \%]$} & {$[0.69 \%]$} \\
\hline \multirow[t]{3}{*}{$M O M_{t+11}$} & $-1.143 * *$ & $-4.899 * * *$ & $-2.224 * * *$ & $-4.806 * * *$ \\
\hline & $(-2.353)$ & $(-5.458)$ & $(-3.995)$ & $(-4.965)$ \\
\hline & [3.90\%] & {$[4.56 \%]$} & {$[4.57 \%]$} & {$[4.26 \%]$} \\
\hline \multicolumn{5}{|c|}{ Panel C. Forecasting Market Volatility using Return Dispersion } \\
\hline \multirow[t]{3}{*}{$M V_{t}$} & $0.520 * * *$ & $1.199 * * *$ & $0.768 * * *$ & $1.223 * * *$ \\
\hline & $(15.900)$ & $(12.050)$ & $(17.910)$ & $(10.820)$ \\
\hline & {$[57.30 \%]$} & [51.80\%] & {$[68.20 \%]$} & {$[47.30 \%]$} \\
\hline
\end{tabular}




\section{Table 8. The Predictive Ability of World Return Dispersion: Sensitivity to US Data}

This table presents panel regressions estimates of the predictive ability of equally or capitalization weighted world return dispersion constructed from non-US stock data for real economic activity (Panel A), market return and factor premia (Panel B) and market volatility (Panel C) for the full period and two sub-periods, 1980-1996 and 1997-2012. In Panel A, economic activity is measured as (a) a dummy variable that takes the value of 1 when the economy is in recession and 0 otherwise (b) the ADS business condition index $\left(A D S_{t}\right)$ and (c) the change in unemployment rate $\left(d U E_{t}\right)$. In Panel B the dependent variables are the twelve month market returns $\left(M r k t_{t+11}\right)$, the value $\left(H M L_{t+11}\right)$, size $\left(S M B_{t+11}\right)$, or momentum $\left(M O M_{t+11}\right)$ premia. In Panel C the dependent variable is the market volatility $(M V)_{t}$. In Panels A and $\mathrm{C}$ predictor variables include world return dispersion and as control variables the average correlation, market return, term spread, the growth in unemployment rate, dividend yield and the short-term nominal interest rate; for the ADS business condition index we also include a lag of the ADS index as control variable. In Panel B predictor variables include the world return dispersion, and as control variables the average correlation, dividend yield and short-term nominal interest rate. The panel model for all equations uses country dummies and clusters the standard errors by country. For all equations except for the $\operatorname{Probit}\left(D_{t}\right)$ we also adjust the standard errors using the Newey-West procedure (Newey and West, 1987) modified for use in a panel data set (see Petersen 2009). For the equations in Panel B Newey-West t-statistics are adjusted for overlapping using the methodology of Britten-Jones, Neuberger and Nolte (2011). t-statistics in parentheses and $\overline{\boldsymbol{R}}^{2}$ in brackets, *Denotes significance at the $10 \%$ level, **Denotes significance at the $5 \%$ level, ***Denotes significance at the $1 \%$ level.

\begin{tabular}{|c|c|c|c|c|c|c|}
\hline & \multirow{2}{*}{\multicolumn{2}{|c|}{$\begin{array}{c}\text { Full Period } \\
1980-2012\end{array}$}} & \multicolumn{4}{|c|}{ Sub-period Analysis } \\
\hline & & & $1980-1996$ & $1997-2012$ & 1980-1996 & $1997-2012$ \\
\hline & $R D_{\text {world,exus }}^{\text {ew }}{ }_{t-1}$ & $R D_{\text {world,exus }}^{c w}{ }_{t-1}$ & $R D_{w o r l d, e x u s_{t-1}^{e w}}^{\text {ew }}$ & $R D_{\text {world,exus }}^{e w-1}$ & $R D_{\text {world,exus }}^{c w-1}$ & $R D_{w o r l d, e x u s}^{c w}{ }_{t-1}$ \\
\hline \multicolumn{7}{|c|}{ Panel A. Return Dispersion and Future Economic Activity } \\
\hline \multirow[t]{3}{*}{$\operatorname{Probit}\left(D_{t}\right)$} & $15.270^{* * *}$ & $9.348^{*}$ & $33.860 * * *$ & $12.000 * * *$ & $10.710^{*}$ & $17.280 * * *$ \\
\hline & $(2.922)$ & $(1.645)$ & $(5.412)$ & $(4.081)$ & $(1.715)$ & $(3.817)$ \\
\hline & {$[23.60 \%]$} & [21.60\%] & {$[45.00 \%]$} & {$[23.70 \%]$} & [40.90\%] & {$[25.10 \%]$} \\
\hline \multirow[t]{3}{*}{$A D S_{t}$} & -0.258 & -0.202 & -0.797 & -0.559 & $2.133^{*}$ & $-1.567^{*}$ \\
\hline & $(-0.404)$ & $(-0.318)$ & $(-0.625)$ & $(-0.771)$ & $(1.871)$ & $(-1.961)$ \\
\hline & [78.70\%] & [78.70\%] & [73.50\%] & [83.90\%] & [73.60\%] & [84.00\%] \\
\hline \multirow[t]{3}{*}{$d U E_{t}$} & $0.163^{* * *}$ & $0.132 * * *$ & $0.137^{*}$ & $0.196 * * *$ & -0.028 & $0.215^{* * *}$ \\
\hline & $(3.631)$ & $(3.024)$ & (1.899) & (3.314) & $(-0.426)$ & (3.699) \\
\hline & {$[9.22 \%]$} & [8.63\%] & [13.60\%] & [8.72\%] & [13.20\%] & {$[8.76 \%]$} \\
\hline \multicolumn{7}{|c|}{ Panel B. Forecasting Market and Factor Premia using Return Dispersion } \\
\hline \multirow[t]{3}{*}{$M r k t_{t+11}$} & $-1.289 * *$ & $-1.254^{*}$ & -1.593 & -0.594 & 0.165 & -1.294 \\
\hline & $(-2.078)$ & $(-1.855)$ & $(-1.534)$ & $(-0.782)$ & $(0.133)$ & $(-1.524)$ \\
\hline & {$[1.26 \%]$} & [1.21\%] & [1.93\%] & [0.69\%] & {$[1.79 \%]$} & {$[0.82 \%]$} \\
\hline \multirow[t]{3}{*}{$H M L_{t+11}$} & $1.364 * * *$ & $1.172 * *$ & 0.362 & $1.782 * * *$ & 0.198 & $1.642 * * *$ \\
\hline & (3.113) & $(2.277)$ & $(0.723)$ & (3.708) & $(0.373)$ & -2.611 \\
\hline & {$[3.83 \%]$} & {$[3.56 \%]$} & {$[2.22 \%]$} & {$[4.70 \%]$} & {$[2.21 \%]$} & {$[4.22 \%]$} \\
\hline \multirow[t]{3}{*}{$S M B_{t+11}$} & -0.270 & 0.120 & -0.503 & 0.041 & 0.545 & -0.042 \\
\hline & $(-0.893)$ & $(0.342)$ & $(-0.776)$ & $(0.125)$ & $(0.934)$ & $(-0.105)$ \\
\hline & {$[0.63 \%]$} & {$[0.62 \%]$} & {$[0.30 \%]$} & {$[0.95 \%]$} & {$[0.32 \%]$} & {$[0.95 \%]$} \\
\hline \multirow[t]{3}{*}{$M O M_{t+11}$} & $-2.008 * * *$ & $-2.402 * * *$ & $-1.568 * *$ & $-3.001 * * *$ & $-1.377^{* *}$ & $-3.439 * * *$ \\
\hline & $(-3.973)$ & $(-4.660)$ & $(-2.278)$ & $(-5.079)$ & $(-2.188)$ & $(-5.192)$ \\
\hline & [4.71\%] & [4.88\%] & {$[5.71 \%]$} & [5.50\%] & {$[5.75 \%]$} & {$[5.26 \%]$} \\
\hline \multicolumn{7}{|c|}{ Panel C. Forecasting Market Volatility using Return Dispersion } \\
\hline \multirow[t]{3}{*}{$M V_{t}$} & $0.595 * * *$ & $0.681 * * *$ & $0.396^{* * *}$ & $0.664 * * *$ & $0.381 * * *$ & $0.804 * * *$ \\
\hline & $(13.120)$ & $(13.050)$ & $(6.969)$ & $(14.070)$ & $(6.629)$ & $(14.910)$ \\
\hline & [54.30\%] & [57.70\%] & [54.80\%] & [60.50\%] & [56.10\%] & [65.90\%] \\
\hline
\end{tabular}


Table 9. The Predictive Power of RD versus Idiosyncratic Volatility (EW)

This table presents panel regressions estimates of the predictive ability of different measures of equally weighted return dispersion ( $R D_{\text {world }}^{e w}$, $R D_{\text {country }}^{\text {ew }}, R D_{\text {portfolio }}^{\text {ew }}$ ) in the presence of equally weighted idiosyncratic volatility (IV $V^{e w}$ ) for real economic activity (Panel A), market returns and factor premia (Panel B) and market volatility (Panel C). In Panel A, economic activity is measured as (a) a dummy variable that takes the value of 1 when the economy is in recession and 0 otherwise $(\mathrm{b})$ the $A D S$ business condition index $\left(A D S_{t}\right)$ and $(\mathrm{c})$ the change in unemployment rate $\left(d U E_{t}\right)$. In Panel B the dependent variables are the twelve month market returns $\left(M r k t_{t+11}\right)$, the value $\left(H M L_{t+11}\right)$, size $\left(S M B_{t+11}\right)$, or momentum $\left(M O M_{t+11}\right)$ premia. In Panel $\mathrm{C}$ the dependent variable is the market volatility $(M V)_{t}$. In Panels $\mathrm{A}$ and $\mathrm{C}$ predictor variables include world return dispersion and idiosyncratic volatility and as control variables the average correlation, market return, term spread, the growth in unemployment rate, dividend yield and the short-term nominal interest rate; for the ADS business condition index we also include a lag of the ADS index as control variable. In Panel B predictor variables include world return dispersion and idiosyncratic volatility and as control variables the average correlation, dividend yield and short-term nominal interest rate. The panel model for all equations uses country dummies and clusters the standard errors by country. For all equations except for the Probit $\left(D_{t}\right)$ we also adjust the standard errors using the Newey-West procedure (Newey and West, 1987) modified for use in a panel data set (see Petersen 2009). For the equations in Panel B Newey-West t-statistics are adjusted for overlapping using the methodology of Britten-Jones,

Neuberger and Nolte (2011). t-statistics in parentheses and $\overline{\boldsymbol{R}}^{2}$ in brackets, *Denotes significance at the 10\% level, **Denotes significance at the 5\% level, *** Denotes significance at the $1 \%$ level.

\begin{tabular}{|c|c|c|c|c|c|c|}
\hline & $R D_{\text {world } t-1}^{e w}$ & $I V_{t-1}^{e w}$ & $R_{\text {country }}^{\text {ew-1 }}$ & $I V_{t-1}^{e w}$ & $R D_{\text {portfolio }}^{\text {ew }}$ & $I V_{t-1}^{e w}$ \\
\hline \multicolumn{7}{|c|}{ Panel A. Return Dispersion, Idiosyncratic Volatility and Future Economic Activity } \\
\hline \multirow[t]{3}{*}{$\operatorname{Probit}\left(D_{t}\right)$} & $9.885^{*}$ & $10.240 * *$ & 5.261 & 11.730 & 4.240 & $14.930 * * *$ \\
\hline & (1.766) & (2.103) & $(0.571)$ & (1.299) & $(0.777)$ & $(4.289)$ \\
\hline & \multicolumn{2}{|c|}{ [28.40\%] } & \multicolumn{2}{|c|}{ [27.70\%] } & \multicolumn{2}{|c|}{ [27.10\%] } \\
\hline \multirow[t]{3}{*}{$A D S_{t}$} & 0.311 & $-1.709 * * *$ & $1.521 *$ & $-2.648 * * *$ & 0.0514 & $-1.470 * * *$ \\
\hline & $(0.422)$ & $(-2.876)$ & (1.924) & $(-3.240)$ & $(0.0391)$ & $(-2.798)$ \\
\hline & \multicolumn{2}{|c|}{ [76.10\%] } & \multicolumn{2}{|c|}{ [76.10\%] } & \multicolumn{2}{|c|}{ [76.30\%] } \\
\hline \multirow[t]{3}{*}{$d U E_{t}$} & $0.123 * * *$ & $0.095 * * *$ & $0.085 *$ & $0.097 * *$ & 0.041 & $0.149 * * *$ \\
\hline & $(2.887)$ & $(2.802)$ & $(1.710)$ & $(2.122)$ & $(0.452)$ & (4.469) \\
\hline & \multicolumn{2}{|c|}{$[8.36 \%]$} & \multicolumn{2}{|c|}{$[7.99 \%]$} & \multicolumn{2}{|c|}{$[7.39 \%]$} \\
\hline
\end{tabular}

Panel B. Forecasting Market and Factor Premia using Return Dispersion and Idiosyncratic Volatility

\begin{tabular}{|c|c|c|c|c|c|c|}
\hline Mrkt $_{t+11}$ & $\begin{array}{c}-2.287 * * * \\
(-3.306)\end{array}$ & $\begin{array}{c}0.692 \\
(0.981)\end{array}$ & $\begin{array}{c}-0.382 \\
(-0.453)\end{array}$ & $\begin{array}{c}-0.254 \\
(-0.306)\end{array}$ & $\begin{array}{c}-6.155^{* * *} \\
(-4.699)\end{array}$ & $\begin{array}{c}0.372 \\
(0.577)\end{array}$ \\
\hline & \multicolumn{2}{|c|}{ [1.72\%] } & \multicolumn{2}{|c|}{ [1.39\%] } & \multicolumn{2}{|c|}{$[4.56 \%]$} \\
\hline$H M L_{t+11}$ & $\begin{array}{c}1.693 * * * \\
(3.530)\end{array}$ & $\begin{array}{c}-0.054 \\
(-0.122)\end{array}$ & $\begin{array}{c}1.848 * * * \\
(3.143)\end{array}$ & $\begin{array}{c}-0.560 \\
(-0.938)\end{array}$ & $\begin{array}{c}4.125^{* * *} \\
(4.310)\end{array}$ & $\begin{array}{c}0.189 \\
(0.461)\end{array}$ \\
\hline & \multicolumn{2}{|c|}{ [3.95\%] } & \multicolumn{2}{|c|}{$[4.03 \%]$} & \multicolumn{2}{|c|}{$[4.52 \%]$} \\
\hline$S M B_{t+11}$ & $\begin{array}{c}-0.250 \\
(-0.717)\end{array}$ & $\begin{array}{c}0.232 \\
(0.715)\end{array}$ & $\begin{array}{c}0.155 \\
(0.353)\end{array}$ & $\begin{array}{c}-0.023 \\
(-0.055)\end{array}$ & $\begin{array}{c}0.061 \\
(0.095)\end{array}$ & $\begin{array}{c}0.096 \\
(0.348)\end{array}$ \\
\hline & \multicolumn{2}{|c|}{ [0.51\%] } & \multicolumn{2}{|c|}{$[0.50 \%]$} & \multicolumn{2}{|c|}{$[0.49 \%]$} \\
\hline$M O M_{t+11}$ & $\begin{array}{c}-2.286^{* * * *} \\
(-4.304)\end{array}$ & $\begin{array}{c}0.616 \\
(1.141)\end{array}$ & $\begin{array}{c}-1.906 * * * \\
(-3.112)\end{array}$ & $\begin{array}{c}0.844 \\
(1.312)\end{array}$ & $\begin{array}{c}-5.227 * * * \\
(-5.477)\end{array}$ & $\begin{array}{c}0.218 \\
(0.411)\end{array}$ \\
\hline & \multicolumn{2}{|c|}{ [4.36\%] } & \multicolumn{2}{|c|}{ [3.98\%] } & \multicolumn{2}{|c|}{ [4.56\%] } \\
\hline \multicolumn{7}{|c|}{ Panel C. Forecasting Market Volatility using Return Dispersion and Idiosyncratic Volatility } \\
\hline$M V_{t}$ & $\begin{array}{c}0.372 * * * \\
(10.010)\end{array}$ & $\begin{array}{c}0.267 * * * \\
(5.712)\end{array}$ & $\begin{array}{c}0.276^{* * *} \\
(5.128)\end{array}$ & $\begin{array}{c}0.259 * * * \\
(3.687)\end{array}$ & $\begin{array}{c}0.632 * * * \\
(7.655)\end{array}$ & $\begin{array}{c}0.348 * * * \\
(7.541)\end{array}$ \\
\hline & \multicolumn{2}{|c|}{ [62.70\%] } & \multicolumn{2}{|c|}{ [59.40\%] } & \multicolumn{2}{|c|}{$[60.80 \%]$} \\
\hline
\end{tabular}


Figure 1. Graphical analysis of Return Dispersion(RD)

This figure plots G7 country measures of monthly (equally and capitalization- weighted) return dispersion. The sample period runs from 1980:07 to 2012:12.

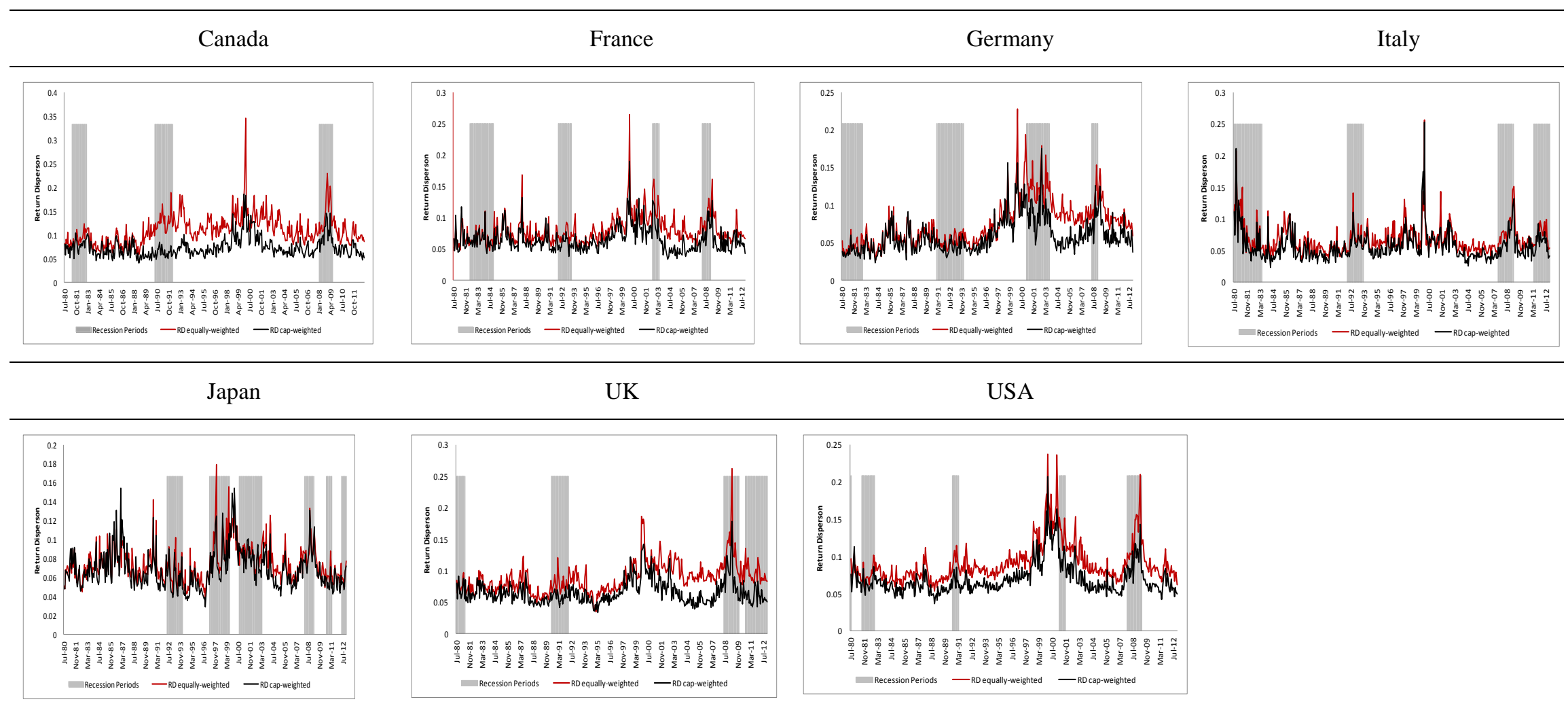




\section{APPENDIX A: Tables}

Table A1. The Predictive Power of RD versus Idiosyncratic Volatility (CW)

This table presents panel regressions estimates of the predictive ability of different measures of equally weighted return dispersion ( $R D_{w o r l d}^{c W}$, $R D_{\text {country }}^{c w}, R D_{\text {portfolio }}^{c w}$ ) in the presence of capitalization weighted idiosyncratic volatility $\left(I V^{c w}\right.$ ) for real economic activity (Panel A), market returns and factor premia (Panel B) and market volatility (Panel C). In Panel A, economic activity is measured as (a) a dummy variable that takes the value of 1 when the economy is in recession and 0 otherwise (b) the $A D S$ business condition index $\left(A D S_{t}\right)$ and (c) the change in unemployment rate (dUE $\left.E_{t}\right)$. In Panel B the dependent variables are the twelve month market returns $\left(M r k t_{t+11}\right)$, the value $\left(H M L_{t+11}\right)$, size $\left(S M B_{t+11}\right)$, or momentum $\left(M O M_{t+11}\right)$ premia. In Panel $\mathrm{C}$ the dependent variable is the market volatility $(M V)_{t}$. In Panels $\mathrm{A}$ and $\mathrm{C}$ predictor variables include world return dispersion and idiosyncratic volatility and as control variables the average correlation, market return, term spread, the growth in unemployment rate, dividend yield and the short-term nominal interest rate; for the ADS business condition index we also include a lag of the ADS index as control variable. In Panel B predictor variables include world return dispersion and idiosyncratic volatility and as control variables the average correlation, dividend yield and short-term nominal interest rate. The panel model for all equations uses country dummies and clusters the standard errors by country. For all equations except for the Probit $\left(D_{t}\right)$ we also adjust the standard errors using the Newey-West procedure (Newey and West, 1987) modified for use in a panel data set (see Petersen 2009). For the equations in Panel B Newey-West t-statistics are adjusted for overlapping using the methodology of Britten-Jones, Neuberger and Nolte (2011). t-statistics in parentheses and $\overline{\boldsymbol{R}}^{2}$ in brackets, *Denotes significance at the 10\% level, **Denotes significance at the 5\% level, ***Denotes significance at the $1 \%$ level.

\begin{tabular}{|c|c|c|c|c|c|c|}
\hline & $R D_{\text {world } t-1}^{c w}$ & $I V_{t-1}^{c w}$ & $R D_{\text {country }}^{c w}{ }_{t-1}$ & $I V_{t-1}^{c w}$ & $R D_{\text {portfolio }}^{c w-1}$ & $I V_{t-1}^{c w}$ \\
\hline \multicolumn{7}{|c|}{ Panel A. Return Dispersion, Idiosyncratic Volatility and Future Economic Activity } \\
\hline \multirow[t]{3}{*}{$\operatorname{Probit}\left(D_{t}\right)$} & 7.958 & 8.483 & -12.960 & $26.980 *$ & 1.577 & $14.920 * *$ \\
\hline & $(1.411)$ & $(1.511)$ & $(-1.016)$ & $(1.790)$ & $(0.118)$ & $(2.302)$ \\
\hline & {$[25.60 \%]$} & & {$[25.70 \%]$} & & {$[24.80 \%]$} & \\
\hline \multirow[t]{3}{*}{$A D S_{t}$} & 1.492 & $-3.172 * * *$ & $3.496 * * *$ & $-5.187 * * *$ & $4.607 * *$ & $-2.904 * * *$ \\
\hline & $(1.502)$ & $(-2.815)$ & $(2.954)$ & $(-3.917)$ & $(2.215)$ & $(-3.466)$ \\
\hline & {$[76.10 \%]$} & & {$[76.20 \%]$} & & {$[76.40 \%]$} & \\
\hline \multirow[t]{3}{*}{$d U E_{t}$} & 0.010 & $0.201 * * *$ & -0.104 & $0.302 * * *$ & -0.165 & $0.241 * * *$ \\
\hline & $(0.157)$ & (2.774) & $(-1.391)$ & $(3.328)$ & $(-1.410)$ & $(4.766)$ \\
\hline & [7.65\%] & & [7.75\%] & & [7.42\%] & \\
\hline \multicolumn{7}{|c|}{ Panel B. Forecasting Market and Factor Premia using Return Dispersion and Idiosyncratic Volatility } \\
\hline \multirow[t]{3}{*}{$\operatorname{Mrkt}_{t+11}$} & $-3.536 * * *$ & 1.417 & -0.614 & -0.732 & $-4.163 * *$ & -0.719 \\
\hline & $(-3.592)$ & $(1.180)$ & $(-0.544)$ & $(-0.567)$ & $(-2.129)$ & $(-0.824)$ \\
\hline & [2.00\%] & & [1.48\%] & & [3.80\%] & \\
\hline \multirow[t]{3}{*}{$H M L_{t+11}$} & $0.986 *$ & 0.794 & 0.835 & 0.799 & 0.954 & $1.396 * * *$ \\
\hline & (1.808) & (1.428) & (1.313) & (1.206) & (1.186) & $(2.725)$ \\
\hline & [3.73\%] & & [3.70\%] & & [0.67\%] & \\
\hline \multirow[t]{3}{*}{$S M B_{t+11}$} & 0.099 & 0.044 & 0.325 & -0.170 & $1.863 * *$ & -0.179 \\
\hline & $(0.248)$ & $(0.103)$ & $(0.621)$ & $(-0.329)$ & $(2.571)$ & $(-0.505)$ \\
\hline & {$[0.50 \%]$} & & {$[0.50 \%]$} & & [4.61\%] & \\
\hline \multirow[t]{3}{*}{$M O M_{t+11}$} & $-1.210^{*}$ & -1.248 & $-1.530 * *$ & -0.801 & $-2.630 * *$ & $-1.752 * *$ \\
\hline & $(-1.847)$ & $(-1.428)$ & $(-1.984)$ & $(-0.812)$ & $(-2.198)$ & $(-2.397)$ \\
\hline & {$[4.58 \%]$} & & [4.54\%] & & [1.83\%] & \\
\hline \multicolumn{7}{|c|}{ Panel C. Forecasting Market Volatility using Return Dispersion and Idiosyncratic Volatility } \\
\hline \multirow[t]{3}{*}{$M V_{t}$} & -0.063 & $0.905 * * *$ & 0.008 & $0.847 * * *$ & -0.020 & $0.856 * * *$ \\
\hline & $(-1.605)$ & (15.380) & $(0.143)$ & (11.150) & $(-0.243)$ & (17.400) \\
\hline & [75.60\%] & & [75.50\%] & & [75.60\%] & \\
\hline
\end{tabular}




\title{
Table A.2. The Economic Significance of Return Dispersion $(R D)$ versus Idiosyncratic Volatility Based Forecasts
}

\begin{abstract}
This table presents the out-of-sample Sharpe ratios of market, value, size and momentum timing strategies using RD or idiosyncratic volatility based forecasts of market returns (Mrkt) and the value $(H M L)$, size $(S M B)$, and momentum (MOM) premia. We produce monthly out-of-sample forecasts of equity premia using equations 5, 6, 7 and 8 estimated recursively using an expanding window approach starting in December 1997. Using premia forecasts and the historical variance-covariance matrix we create portfolios that maximize the Sharpe ratio under the assumption that the portfolio's volatility is equal to the volatility of the buy and hold portfolio. When the estimated market premium is negative we assume that the investor switches her portfolio into cash. We consider three strategies (i) a buy and hold strategy where the investor buys and holds the market portfolio or the three (long-short) factor portfolios (ii) the dispersion strategy (DS) or idiosyncratic strategy (IS) based on RD or idiosyncratic volatility without the control variables and (iii) the full model strategy where the investor utilizes all predictors, including RD or idiosyncratic volatility. Predictor variables include the world return dispersion or idiosyncratic volatility, and control variables (average correlation, dividend yield and short-term nominal interest rate). Results for the equally weighted measures of return dispersion or idiosyncratic volatility are in panel A and for capitalization weighted measures in panel B.
\end{abstract}

\begin{tabular}{|c|c|c|c|c|}
\hline \multicolumn{5}{|c|}{ Panel A. Equally Weighted RD and Idiosyncratic Volatility } \\
\hline & Mrkt & $H M L$ & $S M B$ & MOM \\
\hline \multicolumn{5}{|c|}{ Sharpe Ratio } \\
\hline Buy \& Hold & 0.19 & 0.78 & 0.11 & 0.38 \\
\hline$D S$ & 0.41 & 1.35 & 0.73 & 1.37 \\
\hline$I S$ & 0.39 & 1.24 & 0.79 & 0.94 \\
\hline Full Model_DS & 0.41 & 1.48 & 0.80 & 1.44 \\
\hline Full Model_IS & 0.43 & 1.26 & 0.80 & 1.26 \\
\hline \multicolumn{5}{|c|}{ Panel B. Capitalization Weighted RD and Idiosyncratic Volatility } \\
\hline & Mrkt & $H M L$ & $S M B$ & MOM \\
\hline \multicolumn{5}{|c|}{ Sharpe Ratio } \\
\hline Buy \& Hold Strategy & 0.19 & 0.78 & 0.11 & 0.38 \\
\hline$D S$ & 0.47 & 1.40 & 0.78 & 1.29 \\
\hline$I S$ & 0.43 & 1.33 & 0.77 & 1.27 \\
\hline Full Model_DS & 0.40 & 1.42 & 0.85 & 1.50 \\
\hline Full Model_IS & 0.39 & 1.33 & 0.77 & 1.36 \\
\hline
\end{tabular}




\section{APPENDIX B : Database construction}

1. We include in the database only stocks characterized by Datastream as "equities" (Stock type: EQ).

2. We exclude all companies that are not listed on the primary stock exchange.

3. We use Level 2, Level 3, and Level 4 sector names and the names of the companies to identify and exclude closed end funds, REITs, ADRs and preferred stocks.

4. We set returns as missing if the return index ${ }^{20}$ is below 3 .

5. We set the returns of two consecutive months as missing if we observe an increase over $300 \%$ at month $\mathrm{t}$ and a decrease more than $50 \%$ at month $\mathrm{t}+1$.

6. We set returns as missing if they are higher (lower) than the $97.5^{\text {th }}\left(2.5^{\text {th }}\right)$ percentiles of the daily or monthly return distribution to mitigate the effect of extreme stock returns.

7. We remove $5 \%$ of the stocks with the smallest capitalization.

8. All stocks with less than 10 observations during a month are excluded from the analysis.

${ }^{20}$ A stock is given a total return index value of 100 when entering the database. A return index less than 3 means that the security lost $97 \%$ of its value. 